\title{
The synergistic effect of DZ-NEP, panobinostat and temozolomide reduces clonogenicity and induces apoptosis in glioblastoma cells
}

\author{
JAVIER DE LA ROSA ${ }^{1}$, ALEJANDRO URDICIAIN ${ }^{1}$, IDOYA ZAZPE ${ }^{2}$, MARÍA V. ZELAYA ${ }^{3}$, \\ BÁRBARA MELÉNDEZ ${ }^{4}$, JUAN A. REY ${ }^{5}$, MIGUELA. IDOATE ${ }^{6}$ and JAVIER S. CASTRESANA ${ }^{1}$ \\ ${ }^{1}$ Department of Biochemistry and Genetics, University of Navarra School of Sciences; \\ Departments of ${ }^{2}$ Neurosurgery and ${ }^{3}$ Pathology, Hospital Complex of Navarra, 31008 Pamplona; \\ ${ }^{4}$ Molecular Pathology Research Unit, Department of Pathology, Virgen de la Salud Hospital, \\ 45005 Toledo; ${ }^{5}$ diPaz Research Unit, La Paz University Hospital, 28046 Madrid; \\ ${ }^{6}$ Department of Pathology, University of Navarra Clinic, 31008 Pamplona, Spain
}

Received March 26, 2019; Accepted August 29, 2019

DOI: 10.3892/ijo.2019.4905

\begin{abstract}
Current treatment against glioblastoma consists of surgical resection followed by temozolomide, with or without combined radiotherapy. Glioblastoma frequently acquires resistance to chemotherapy and/or radiotherapy. Novel therapeutic approaches are thus required. The inhibition of enhancer of zeste homolog 2 (EZH2; a histone methylase) and histone deacetylases (HDACs) are possible epigenetic treatments. Temozolomide, 3-deazaneplanocin A (DZ-Nep; an EZH2 inhibitor) and panobinostat (an HDAC inhibitor) were tested in regular and temozolomide-resistant glioblastoma cells to confirm whether the compounds could behave in a synergistic, additive or antagonistic manner. A total of six commercial cell lines, two temozolomide-induced resistant cell lines and two primary cultures derived from glioblastoma samples were used. Cell lines were exposed to single treatments of the drugs in addition to all possible two- and three-drug combinations. Colony formation assays, synergistic assays and reverse transcription-quantitative PCR analysis of apoptosis-associated genes were performed. The highest synergistic combination was DZ-Nep + panobinostat. Triple treatment was also synergistic. Reduced clonogenicity and increased apoptosis were both induced. It was concluded that the therapeutic potential of the combination of these three drugs in glioblastoma was evident and should be further explored.
\end{abstract}

Correspondence to: Professor Javier S. Castresana, Department of Biochemistry and Genetics, University of Navarra School of Sciences, Irunlarrea 1, 31008 Pamplona, Spain

E-mail: jscastresana@unav.es

Key words: 3-deazaneplanocin A, epigenetics, enhancer of zeste homolog 2, glioblastoma, histone deacetylase, panobinostat

\section{Introduction}

Glioblastoma $(1,2)$ is the most common form of malignant brain cancer in adults. It is highly lethal, with a median survival of $<15$ months (3). Surgery, radiation therapy and temozolomide are the main therapeutic options against glioblastoma. A lack of expression of methyl guanyl methyltransferase [MGMT; a DNA repair enzyme (4) that reverses the temozolomide-induced $\mathrm{O}^{6}$ guanine methylation] due to MGMT promoter methylation is associated with improved clinical response to temozolomide, whereas patients with unmethylated MGMT promoters exhibit resistance to temozolomide (4). Temozolomide resistance and radiotherapy resistance represent major challenges in the treatment of this disease $(3,5,6)$.

Brain tumors are not only developed by gene mutation, but also by epigenetic changes, mainly DNA methylation, histone acetylation, histone methylation and microRNA dysregulation (7-11). Unlike genetic alterations, epigenetic changes are reversible, and as such are considered attractive targets for cancer therapy. Two main epigenetic modulators were investigated in the present study, one that targets the enhancer of zeste homolog 2 (EZH2) histone methyltransferase [3-deazaneplanocin A (DZ-Nep) (12)], and a second one that targets histone deacetylases (HDACs), panobinostat (13).

EZH2, the catalytically active component of polycomb repressive complex 2, trimethylates lysine 27 of histone H3 (H3K27met3) (14). EZH2 is overexpressed in ovarian carcinoma (15), prostate cancer (16), glioblastoma (17) and other tumors, and predicts poor prognosis, high tumor grade and high clinical stage (18) by favoring cell invasion and tumor angiogenesis. DZ-Nep, an inhibitor of EZH2, demonstrated antitumor activity against breast (19), lung (20), brain (21), prostate (22) and liver (23) cancer cells, blocked cancer cell migration and invasion in prostate cancer cells (22), and reduced tumor-associated blood vessel formation in a glioblastoma xenograft model, suggesting antiangiogenic activity in vivo $(18,24)$. Recent studies have reinforced the value of EZH2 as a target in cancer, even associated microRNAs and long non coding RNAs with the regulation of EZH2 (25-27). 
Histone acetylation by histone acetyltransferases induces a relaxed status of chromatin and promotes the expression of adjacent genes, whereas HDACs condense chromatin and inhibit gene expression. One proposed strategy against cancer is the use of inhibitors of HDACs, such as panobinostat (28-33), that target certain pathways that serve important roles in cancer development (13,34-36) at the level of the cell cycle, apoptosis, DNA damage responses, metastasis, angiogenesis or autophagy.

The aim of the present study was to investigate the therapeutic potential of different combinations of DZ-Nep, panobinostat and temozolomide for the in vitro treatment of glioblastoma, as well as the possible synergistic effects that could exist between them.

\section{Materials and methods}

In vitro culture of cell lines and primary tumors Cell lines. A172 (CRL1620), U87MG (HTB14), T98G (92090213), MOG-C-CCM (86022702), LN405 (ACC189), and GOS-3 (ACC408) human glioblastoma cell lines were used for the study. A172 and U87MG (glioblastoma of unknown origin) were obtained from the American Type Culture Collection. T98G and MOG-C-CCM were obtained from the European Collection of Authenticated Cell Cultures. LN405 and GOS-3 were obtained from the German Collection of Microorganisms and Cell Cultures GmbH. A172, GOS-3, T98G, MOG-C-CCM, LN405 cells were cultured using RPMI L-Glutamax medium (Gibco; Thermo Fisher Scientific, Inc.), supplemented with $10 \%$ fetal bovine serum (FBS; Gibco; Thermo Fisher Scientific, Inc.), $1 \%$ penicillin/streptomycin (Gibco; Thermo Fisher Scientific, Inc.) and $0.1 \%$ amphotericin B (Gibco; Thermo Fisher Scientific, Inc.). U87MG cells were cultured using DMEM L-Glutamax (Gibco; Thermo Fisher Scientific, Inc.) supplemented with $10 \%$ FBS, $4 \%$ non-essential amino acids, $1 \%$ penicillin/streptomycin and $0.1 \%$ amphotericin B. Cells were maintained under normoxic conditions at $37^{\circ} \mathrm{C}$ with a humid atmosphere of $5 \% \mathrm{CO}_{2}$. Subcultures were performed upon reaching $\sim 80 \%$ confluence using trypsin/EDTA (Gibco; Thermo Fisher Scientific, Inc.), after a previous wash with phosphate buffered saline (PBS; Gibco; Thermo Fisher Scientific, Inc.). Table I presents the molecular profiles of the cell lines used.

Obtaining temozolomide-resistant cell lines. Cell lines A172 and LN405 were exposed to $500 \mu \mathrm{M}$ temozolomide for $72 \mathrm{~h}$ at $37^{\circ} \mathrm{C}$ in an atmosphere of $5 \% \mathrm{CO}_{2}$. The surviving cells were subsequently allowed to grow until they developed colonies. The colonies were trypsinized and reseeded. Once the cells reached $\sim 70 \%$ confluence, they were treated again with temozolomide as aforementioned. There were three total exposures to temozolomide. The cell lines obtained, with increased resistance to temozolomide, were designated A172-TMZR and LN405-TMZR, and were cultured under the same conditions as the parental cells from which they were derived.

Every 10 passes, a recall dose $(500 \mu \mathrm{M})$ was followed by a rest step as described above. Regarding the final dose of temozolomide to which cells were resistant to, note that it was not intended for the resistant cells to acquire resistance to a dose of temozolomide at which all parental cells would die,
Table I. Molecular profile of PTEN and p53 genes in cell lines and primary cell cultures.

\begin{tabular}{llll}
\hline Cell line & Type & \multicolumn{1}{c}{ PTEN } & \multicolumn{1}{c}{ p53 } \\
\hline A172 & GB & MUT (60) & WT (61) \\
A172-TMZR & GB & MUT (60) & WT (61) \\
U87MG & GB & MUT (62) & WT (61) \\
LN405 & GB & MUT $^{\mathrm{a}}$ & MUT $^{\mathrm{a}}$ \\
LN405-TMZR & GB & MUT $^{\mathrm{a}}$ & MUT $^{\mathrm{a}}$ \\
T98G & GB & MUT (63) $_{\text {GOS-3 }}$ & MUT (61) $_{\text {GB }}$ \\
MOG-G-CCM & GB & hemi-METH (64) & WT (65) \\
PE8 & GB-1 & ND & MUT (66) \\
PE9 & GB-1 & ND & ND \\
\hline
\end{tabular}

anformation obtained from https://amp.pharm.mssm.edu/ Harmonizome/gene_set/LN-405/COSMIC+Cell+Line+Gene+Mutat ion+Profiles. GB, glioblastoma; GB-1, primary glioblastoma; MUT, mutated; WT, wild type; ND, not determined; METH, methylated.

but that the resistant lines exhibited greater resistance to the drug (particularly A172, as LN405 started with a large basal resistance).

Culture of primary tumors. The study was authorized by the Ethics Committee of the University of Navarra (ref. no. CEI0502012) for conducting research on the genetics of tumors of the nervous system. All samples were fully anonymized prior to accessing; therefore, patient details were not known. Patients provided informed consent for the use of their samples for research. Primary tumors obtained from the Hospital Complex of Navarra were cultured. Tumor fragments were completely frozen in vials at $-80^{\circ} \mathrm{C}$ and in liquid nitrogen. The remainder of the tumor tissue was cut with scalpels into $\sim 22-\mathrm{mm}$ thick fragments, which were treated with $0.1 \%$ trypsin and later mechanically processed until tumor tissue was disintegrated into individual cells. The cells were cultured in flasks pretreated with laminin in neurosphere medium (composition described below). Starting with $1 \mathrm{mg} / \mathrm{ml}$ laminin (Sigma-Aldrich; Merck KGaA), a $10 \mu \mathrm{g} / \mathrm{ml}$ final concentration solution was prepared using PBS. The culture flasks were treated by adding $3 \mathrm{ml}$ of this solution. After incubating the flasks overnight at $4^{\circ} \mathrm{C}$, excess laminin was removed and three washes were made with $3 \mathrm{ml}$ of PBS. The culture medium used was DMEM + F12 (Gibco; Thermo Fisher Scientific, Inc.) in the absence of serum and supplemented with 1X B27 (Gibco; Thermo Fisher Scientific, Inc.), $20 \mathrm{ng} / \mathrm{ml}$ epidermal growth factor (Sigma-Aldrich; Merck KGaA) and $20 \mathrm{ng} / \mathrm{ml}$ basic fibroblast growth factor (Sigma-Aldrich; Thermo Fisher Scientific, Inc.). The cell lines derived from primary tumors used in this study were termed PE8 and PE9. Short tandem repeat (STR) profiles of both cell lines were analyzed (Figs. S1 and S2) and the resulting alleles of 16 STR loci are listed for further matching studies (Tables SI and SII).

Experiments were performed using the primary tumor cell lines throughout the study with the various combinations of drugs, ensuring that cells did not undergo $>20$ passes. 
Pharmacological treatments. DZ-Nep, panobinostat and temozolomide (all Sigma-Aldrich; Merck KGaA), in individual or combined treatments, were used to treat the cell lines and primary cultures under investigation. A stock solution of the drugs was prepared by diluting them in DMSO at a concentration of $33.45 \mathrm{mM}$ (DZ-Nep), $500 \mu \mathrm{M}$ (panobinostat), and $51.5 \mathrm{mM}$ (temozolomide). The drugs were stored in aliquots at $-20^{\circ} \mathrm{C}$ (DZ-Nep and temozolomide) or $-80^{\circ} \mathrm{C}$ (panobinostat). Each drug was diluted in medium to the corresponding concentration for each experiment. All experimental treatments were performed with the same quantity of DMSO diluted in medium, always $<0.1 \%$. Control treatments entailed treatment with DMSO $(<0.1 \%)$ only diluted in medium.

Analysis of cell viability using MTT. Cell viability was measured using an MTT colorimetric assay from Sigma-Aldrich (Merck $\mathrm{KGaA}$ ). Cells were seeded in 96-well plates at a density of 5,000 cells/well, and 8 replicates were used for each control and each treatment. Cells were treated with different concentrations of each drug for $0,24,48$ and $72 \mathrm{~h}$ at $37^{\circ} \mathrm{C}$. The concentrations employed for DZ-Nep and temozolomide spanned a spectrum from 1-200 $\mu \mathrm{M}$. Panobinostat treatments covered a range of $0.001-200 \mu \mathrm{M}$. After the aforementioned treatment durations, MTT solution $(0.5 \mathrm{mg} / \mathrm{ml})$ was added to the plates and incubated for $2 \mathrm{~h}$. After incubation, the medium was removed and DMSO was added to the plates to dissolve the formazan precipitates. The absorbance was measured at $550 \mathrm{~nm}$.

Study of the synergy between drugs according to the combination index (CI)

Definition of synergy. The combination of multiple treatments in glioblastoma is a requirement imposed due to the genetic heterogeneity of this type of brain tumor $(37,38)$. A treatment with a single active compound can lead to an incomplete eradication of the tumor, or even to the appearance of resistance against that particular compound; however, not all combinations of chemotherapeutics are equally effective. Ideally, the objective of treatment is the potentiation of the pharmaceutical effect on the tumor, observing a response greater than predicted. This enhancement is referred to as synergy, and may be due to a feedback between the mechanisms of action of the two drugs. The effect observed when the combination of the two drugs is less effective than the application of the two drugs separately is known as antagonism. An additive effect would correspond to the effect observed when there is an absence of antagonism or synergy; that is, when the effect produced by the two drugs supplied simultaneously corresponds to the addition of the effects produced by the two drugs supplied individually.

However, finding a mathematical model that explains the antagonistic, additive or synergistic effects is a controversial issue $(39,40)$. For example, if drug $\mathrm{A}$ is able to eliminate $30 \%$ of the tumor at a certain dose, and drug B another $30 \%$ at a given dose, assuming, as a consequence, that $60 \%$ of the tumor would be eliminated if the two drugs followed an additive model would be an excessive mathematical simplification. This and other simplistic mathematical approaches have led to an erroneous application of the concept of synergy in several pharmacological studies (41).
Chou-Talalay's CI. Other mathematical approaches consider the different non-linear forms of the dose/effect curves that can stop the different drugs, and attempt to determine which concentration of each drug is capable of producing an equivalent quantitative effect. These approaches are known as dose-effect strategies (42), and in them the putative additive effect of a combination depends on the individual dose-effect curves and follows the mathematical model of Loewe's addiction (43). Chou and Talalay designed a simple equation (Fig. S3A) capable of representing the synergistic effect evaluated in vitro as a CI. Without entering into the mathematical details of this equation, it could be summarized as follows: For a combined dose of two drugs (A and B) for which a certain affected cellular fraction $(\mathrm{Fa})$ is observed, the CI would correspond to the sum of the fractions of the doses of each drug in combination [(Dcomb $)_{1}$ or(Dcomb $)_{2}$ ] divided by the dose of each individual drug at which the same effect is observed [(Dalone $)_{1}$ or (Dalone) ${ }_{2}$ ]. If $\mathrm{CI}<1$, the combination could be considered synergistic; if $\mathrm{CI}>1$, the combination would be antagonistic; and $\mathrm{CI}=1$ would be equivalent to an additive effect (Fig. S3A).

One of the advantages of this equation is the assessment of the synergy for each Fa. The higher the concentration of drugs (supplied individually or in combination), the higher the $\mathrm{Fa}$ of the affected population. However, synergy does not necessarily have to be constant through all the fractions affected by the treatment of a combination of drugs at different concentrations.

A study of in vitro synergy could provide infinite combinations of concentrations of two drugs. Therefore, Chou (44) recommends testing the drug combinations following a constant ratio. Drug concentrations are so mixed following a constant ratio and administered in combination, from lower to higher doses. A good approximation is to use the half-maximal inhibitory concentration (IC) of each drug in a 1:1 ratio so that each compound has the same potency in the combination. However, due to the nature of each chemotherapeutic, this can be difficult to determine, rendering it necessary to work with other quotients. For example, one of the drugs may have lower solubility, or may be more difficult to obtain due to economic reasons, or it may even be the case that the margin in which an effect proportional to the dose delivered is observed is very narrow. In those cases, combinations of drugs may be tested following a non-constant ratio of drug concentrations.

Use of Compusyn software in the combinatorial study of drugs. The free Compusyn software (http://www.combosyn. com/), developed by Chou's group, allows rapid collection of the ICs calculated for each drug combination. Its representation in graphs with the ICs of each drug combination against their respective Fa (Fig. S3A) (44) is a useful tool that greatly simplifies the analysis of drug combinations.

Study of the combination of $\geq 3$ drugs. Often, the possible synergy of drugs is analyzed by the combination of compounds in pairs, which facilitates understanding of the results, as it represents a common situation in clinical practice. Using combinations of $\geq 3$ drugs is less common clinically. The CI equation proposed by Chou and Talalay can be used for the analysis of $>2$ drugs, and the Compusyn program allows the study of the synergy of up to three simultaneous drugs. However, it must be considered that the synergy obtained 
Table II. Experimental concentrations of compounds.

A, Concentrations used for in vitro experiments $(\mu \mathrm{M})$

\begin{tabular}{lccc}
\hline Cell line & DZ-Nep & Panobinostat & Temozolomide \\
\hline A172 & 5 & 0.02 & 0.2 \\
A172-TMZR & 5 & 0.02 & 0.2 \\
U87MG & 5 & 0.02 & 0.2 \\
LN405 & 5 & 0.02 & 0.2 \\
LN405-TMZR & 5 & 0.02 & 0.2 \\
T98G & 5 & 0.02 & 0.2 \\
GOS-3 & 5 & 0.02 & 0.2 \\
MOG-G-CCM & 5 & 0.02 & 0.2 \\
PE8 & 5 & 0.02 & 0.2 \\
PE9 & 5 & 0.02 & 0.2 \\
\hline
\end{tabular}

$\mathrm{B}$, Concentrations used for combinatorial experiments $(\mu \mathrm{M})$

\begin{tabular}{lccc}
\hline Cell line & DZ-Nep & Panobinostat & Temozolomide \\
\hline U87MG & $5-80(5,10,20,40,80)$ & $0.01-0.16(0.01,0.02,0.04$, & $12.5-200(12.5,25,50$, \\
& & $0.08,0.16)$ & $100,200)$ \\
LN405 & $5-80$ & $0.01-0.16$ & $12.5-200$ \\
LN405-TMZR & $5-80$ & $0.01-0.16$ & $12.5-200$ \\
GOS-3 & $5-80$ & $0.01-0.16$ & $12.5-200$ \\
MOG-G-CCM & $5-80$ & $0.01-0.16$ & $12.5-200$ \\
\hline
\end{tabular}

$\mathrm{C}$, Concentrations used for triple combinations $(\mu \mathrm{M})$

\begin{tabular}{lccc}
\hline Cell line & DZ-Nep & Panobinostat & Temozolomide \\
\hline U87MG & $1.66-26.67(1.667,3.333$, & $0.003-0.053(0.003,0.007$, & $4.167-66.67(4.167,8.333$, \\
& $6.667,13.333,26.667)$ & $0.013,0.027,0.053)$ & $16.667,33.333,66.667)$ \\
LN405 & $1.66-26.67$ & $0.003-0.053$ & $4.167-66.67$ \\
LN405-TMZR & $1.66-26.67$ & $0.003-0.053$ & $4.167-66.67$ \\
GOS-3 & $1.66-26.67$ & $0.003-0.053$ & $4.167-66.67$ \\
MOG-G-CCM & $1.66-26.67$ & $0.003-0.053$ & $4.167-66.67$
\end{tabular}

DZ-Nep, 3-deazaneplanocin A.

by the use of $\geq 3$ drugs may be due solely to the synergistic effect of two of these drugs. Therefore, special care must be taken when interpreting the results of these analyses (45). In the present study, Compusyn was used for the combinatorial analysis of three different drugs: DZ-Nep, panobinostat and temozolomide. The drugs were combined in pairs or triplets. All combinations were studied following a constant ratio.

Drug combination studies and their synergy quantification. A drug combination study was conducted to determine the synergistic potential of the drugs used according to the Chou-Talalay method (46). Commercial cell lines were used; however, due to their slower proliferation, cell lines derived from primary tumors were not used. Cells (5,000/well) were seeded in 96-well plates. The following day, the culture medium was replaced with fresh medium containing combinations of
5 different concentrations for each drug (Table II). The effects of DZ-Nep, panobinostat and temozolomide administered individually or in combination were studied for $72 \mathrm{~h}$. At the same time, whether pre-treatment of a drug followed by a post-treatment of a separate drug was a more efficient therapeutic strategy than simultaneous double combination treatment was evaluated. For this, 5,000 cells per well were seeded in 96-well plates, and the following day the medium was changed by 5 different concentrations of each of the drugs to be used in each pre-treatment. At $24 \mathrm{~h}$ later, the medium was removed and changed to 5 different concentrations of each of the possible post-treatments, allowing them to incubate for $48 \mathrm{~h}$. In any case, the experiments with combined treatment or with individual pre-treatment followed by post-treatment were not incubated for longer than $72 \mathrm{~h}$. After incubation, MTT 
Table III. Sequences of the primers used for quantitative PCR.

\begin{tabular}{llllc}
\hline Gene & \multicolumn{1}{c}{ Forward primer $\left(5^{\prime}-3^{\prime}\right)$} & \multicolumn{1}{c}{ Reverse primer $\left(5^{\prime}-3 '\right)$} & Tm $\left({ }^{\circ} \mathrm{C}\right)$ & Annealing temperature $\left({ }^{\circ} \mathrm{C}\right)$ \\
\hline GAPDH & AACGTGTCAGTGGTGGACCTG & AGTGGGTGTCGCTGTTGAAGT & 67.4 & 63.4 \\
BAX & TTTGCTTCAGGGTTTCATCC & CAGTTGAAGTTGCCGTCAGA & 60 & 56 \\
NOXA & CTTGGAAACGGAAGATGGAA & CGCCCAGTCTAATCACAGGT & 60 & 56 \\
BCL2 & GGATGCCTTTGTGGAACTGT & AGCCTGCAGCTTTGTTTCA & 60 & 56 \\
BCL-XL & TCTGGTCCCTTGCAGCTAGT & CAGGGAGGCTAAGGGGTAAG & 60 & 56
\end{tabular}

Tm, melting temperature.

reagent was added at a concentration of $0.5 \mathrm{mg} / \mathrm{ml}$, and the plates were incubated for $2 \mathrm{~h}$ at $37^{\circ} \mathrm{C}$. The absorbance was measured at $550 \mathrm{~nm}$, and the percentage of surviving cells was determined for each treatment in relation to untreated control cells. The Fa was determined, which represents the inhibition of the respective proliferation at each treatment, whereby an inhibition of $0 \%$ corresponds to $\mathrm{Fa}=0$, and an inhibition of $100 \%$ corresponds to $\mathrm{Fa}=1$. CI values were calculated and represented using dose-response graphs in Compusyn software (47). All combinations of drugs were analyzed using a constant ratio (DZ-Nep, $5 \mu \mathrm{M}$; panobinostat, $0.01 \mathrm{nM}$; temozolomide, $12.5 \mu \mathrm{M}$ ). Drug concentrations are presented in Table II.

In vitro pharmacological effect. Cell lines and cells derived from primary tumors were incubated for $72 \mathrm{~h}$ with DZ-Nep, panobinostat and temozolomide, according to Table II $(33,48,49)$. Treatments were performed with individual drugs or two-drug combinations. After $72 \mathrm{~h}$ of incubation, the cell culture medium was removed and replaced with medium supplemented with fresh drug every $24 \mathrm{~h}$. After incubation, cells were trypsinized, counted and used to perform the in vitro functional experiments. Part of the cells were frozen at $-80^{\circ} \mathrm{C}$ for subsequent extraction of mRNA and proteins. All in vitro experiments (apoptosis, soft agar colony formation and colony formation assays on plate) were performed in triplicate.

Apoptosis assay. The effects of drugs on the activation of caspase-mediated apoptosis were studied in A172, A172-TMZR and LN405 cells. For this, 5,000 cells/well were plated in 96-well plates for $24 \mathrm{~h}$, after which the culture medium was replaced by cell medium containing drugs at the following concentrations: $5 \mu \mathrm{M}$ DZ-Nep, $20 \mathrm{nM}$ panobinostat and/or $200 \mathrm{nM}$ temozolomide. Drugs were tested individually or in pairs. Cells were incubated at $37^{\circ} \mathrm{C}$ with the drugs for $2 \mathrm{~h}$. Then, the activity levels of caspases 3 and 7 were quantified by luminescence using a Caspase-Glo ${ }^{\circledR}$ 3/7 Assay kit (cat. no. G8090; Promega Corporation), according to the manufacturer's protocols.

Soft agar colony formation assay. To study in vitro cell tumorigenicity under conditions of anchorage independence, cells were seeded in agarose in 6-well plates. For this, a solution containing $2 \mathrm{ml}$ of $0.5 \%$ agarose (Pronadisa; Laboratorios Conda) and DMEM (Sigma-Aldrich; Merck KGaA) was first added to each well. Once this first agarose layer had set, 10,000 cells diluted in $2 \mathrm{ml}$ of $0.2 \%$ agarose and DMEM were added. When this second layer solidified, $2 \mathrm{ml}$ of the corresponding culture medium of each cell line supplemented with $10 \%$ FBS was added to each well and renewed every 3 days. After 4 weeks of incubation, the medium was removed and the colonies were stained with $250 \mu \mathrm{l}$ of $1 \%$ crystal violet (Sigma-Aldrich; Merck $\mathrm{KGaA}$ ) overnight at $4^{\circ} \mathrm{C}$. Five washes with autoclaved water were performed to improve cell visualization. Images were acquired ( 5 photos/well) under a microscope (magnification, $\mathrm{x} 10$ ), and the colonies formed in each visual field were counted. The different pharmacological conditions were seeded in triplicate for each cell line in three independent experiments. This assay was not performed on A172, A172-TMZR, GOS-3 and MOG-C-CCM cells, due to sub-optimal cell growth under these experimental conditions.

Colony formation assay in adherent conditions. To study cellular clonogenicity under anchoring conditions, the treated cells were seeded in 6-well plates, and allowed to incubate for 14 days. Then, the medium was removed and the cells were fixed using 4\% paraformaldehyde (Panreac AppliChem ITW Reagents) for $30 \mathrm{~min}$, after which they were stained with $1 \%$ crystal violet for $15 \mathrm{~min}$ (both at room temperature). The colonies formed were counted using a Colony Counter 560 (Suntex Instruments Co., Ltd.). The number of cells seeded varied depending on the cell line; 300 cells/well were seeded for all cell lines, with the exception of PE8, PE9 and GOS-3, for which 700 cells/well were seeded.

\section{Molecular studies}

$m R N A$ extraction and reverse transcription $(R T)$. mRNA was extracted from the treated cell pellets for $72 \mathrm{~h}$ with the different drug conditions using an All Prep DNA/RNA/Protein Mini kit (Qiagen $\mathrm{GmbH}$ ), according to the manufacturer's protocols. The mRNA concentration was determined using a NanoDrop $^{\mathrm{TM}}$ system (NanoDrop Technologies; Thermo Fisher Scientific, Inc.).

The RT of mRNA to cDNA was performed using $2 \mu \mathrm{g}$ of RNA, $250 \mu \mathrm{g}$ of random primers and $2 \mu \mathrm{l}$ of dNTPs (stock $5 \mu \mathrm{M}$ ) in a final volume of $12 \mu \mathrm{l}$ of RNase-free water. The mixture was incubated at $65^{\circ} \mathrm{C}$ for $5 \mathrm{~min}$, after which $4 \mu \mathrm{l}$ of $5 \mathrm{X}$ buffer and $2 \mu \mathrm{l}$ of DTT were added. After $2 \mathrm{~min}$ at $42^{\circ} \mathrm{C}$, $1 \mu \mathrm{l}$ of the enzyme SuperScript ${ }^{\mathrm{TM}}$ II Reverse Transcriptase (Gibco; Thermo Fisher Scientific, Inc.) was added and incubated at $25^{\circ} \mathrm{C}$ for $10 \mathrm{~min}$, at $42^{\circ} \mathrm{C}$ for $50 \mathrm{~min}$ and at $70^{\circ} \mathrm{C}$ for $15 \mathrm{~min}$. The obtained cDNA was diluted $1 / 5$ in autoclaved water and stored at $-20^{\circ} \mathrm{C}$ until subsequent use.

Quantitative PCR ( $q P C R)$. Gene expression was measured via RT-qPCR. The design and analysis of each pair of primers 
was conducted using Primer3 software (http://primer3. sourceforge.net/) and Primer Blast (http://www.ncbi.nlm. nih.gov/tools/primer-blast/). Primer sequences are shown in Table III. The primers used were selected and aligned with the nucleotide sequences obtained from RefSeq (http://www. ncbi.nlm.nih.gov/RefSeq/) and UCSC Genome Browser (http://genome.ucsc.edu/).

For RT-qPCR reactions, an IQ5 Multicolor Real-Time PCR Detection System (Bio-Rad Laboratories, Inc.) was used. In each well, $1.25 \mu \mathrm{l}$ cDNA, $12.5 \mu \mathrm{l} \mathrm{iQ}^{\mathrm{TM}} \mathrm{SYBR}^{\circledR}$ Green (cat. no. 1708882 Bio-Rad Laboratories, Inc.), $0.5 \mu 1$ sense and antisense primers and $10.25 \mu \mathrm{l}$ milliQ autoclaved water were added. The samples were subjected to the following protocol: Initial denaturation cycle at $95^{\circ} \mathrm{C}$ for $10 \mathrm{~min}$, followed by 45 cycles of amplification comprising $30 \mathrm{sec}$ at $95^{\circ} \mathrm{C}, 30 \mathrm{sec}$ at the annealing temperature of each pair of primers, and $30 \mathrm{sec}$ at $72^{\circ} \mathrm{C}$. After the amplification step, the melting temperature curve was analyzed from $70^{\circ} \mathrm{C}$ to $90^{\circ} \mathrm{C}$, with a $0.5^{\circ} \mathrm{C}$ increased at every $30 \mathrm{sec}$. The transcripts of the genes were normalized with the transcripts of the GAPDH control gene in each sample. Quantification and normalization of the genes was performed using the $2^{-\Delta \Delta \mathrm{Cq}}$ method (50), which allows the relative expression of the genes in a study to be quantified. Three independent experiments were performed with the samples subjected to a triplicate amplification protocol.

Statistical analysis. Three independent experiments were performed. All data are presented as the mean \pm standard deviation. All data are normalized with respect to controls. To analyze the differences observed between the different pharmacological conditions, ANOVA was performed followed by Tukey's post hoc test using GraphPad Prism 7 software (GraphPad Software, Inc.). $\mathrm{P}<0.05$ was considered to indicate a statistically significant difference.

\section{Results}

Development of temozolomide-resistant glioblastoma cell lines. In this study a range of cell lines with different $p 53$ and PTEN gene statuses were employed, with different sensitivities to temozolomide. The lines were selected based on their molecular status for these genes documented in the literature. In addition, the development of temozolomide resistance was mimicked by exposing the cell lines A172 (p53wt/PTENmut) and LN405 (p53mut/PTENmut) to a concentration of $500 \mu \mathrm{M}$ of temozolomide. The resulting cell lines were designated A172-TMZR and LN405-TMZR (Table I). Fig. S3B shows the increase in resistance to temozolomide in these two cell lines. A172-TMZR showed a significant increase in resistance to temozolomide compared with A172 at the highest concentrations studied $(\mathrm{P}<0.001)$. LN405-TMZR cells exhibited a significant increase in resistance to temozolomide at very high concentrations of this drug compared with LN405 cells $(\mathrm{P}<0.05)$. It should be considered, however, that the LN405 line is naturally more resistant to temozolomide than the A172 line, which may explain the differences in the resistance acquired to this drug by each cell line. Also, it would be of interest to see whether, after the treatments, cells may develop vulnerabilities to the other drugs. Those vulnerabilities may be similar to those of the other temozolomide-resistant cell lines (51).
DZ-Nep + panobinostat combined treatment

DZ-Nep + panobinostat combined treatment shows an additive/synergistic effect at the highest concentrations. In DZ-Nep + panobinostat combined treatment, a consistenttendency towards synergy was not observed in all cell lines. Simultaneous treatments resulted a greater Fa than the therapies performed with pre-treatment and post-treatment (Table SIII).

All concentrations used in double simultaneous treatments turned out to be synergistic in U87MG cells, whereas for the other cell lines, synergistic effects appeared only in the treatment combinations that resulted in a greater $\mathrm{Fa}$, as confirmed by the predictions obtained by Compusyn. These predictions indicated a clear synergistic effect in DZ-Nep + panobinostat combined treatment in the majority of cell lines; however, an additive effect was predicted in the LN405 cell line, while in LN405-TMZR, the prediction indicated that the combination was antagonistic.

Conversely, predictions of pre-treatment therapies followed by post-treatment do not appear to show a clear tendency to synergy. Pre-treatment with DZ-Nep shows synergy with panobinostat post-treatment in MOG-G-CCM cells, whereas the pre-treatment with panobinostat shows the greatest synergy in U87MG cells.

LN405 and LN405-TMZR cells, although showing less synergism to the double simultaneous treatment of DZ-Nep + panobinostat, clearly exhibited synergistic CI indexes in this therapeutic strategy. Even so, DZ-Nep + panobinostat double simultaneous treatment was the one that induced the highest elevated fractions, indicating this as the most promising therapeutic strategy for clinical settings. The ICs obtained (Table SIII) were plotted on a logarithmic scale in Fig. S4 using the Compusyn program.

Regarding GOS-3 (Table SIII), there is synergy only for the panobinostat pre-treatment/DZ-Nep post-treatment and at certain concentrations of DZ-Nep pre-treatment/panobinostat post-treatment. Compusyn predicts synergy at higher concentrations for the simultaneous 72-h (D72P72) treatment (Fig. S4), whereas for the other treatments it does not predict synergy. Simultaneous D72P72 treatment produces high, non-synergistic indices, potentially because the Fa values obtained are low. Thus, synergy is predicted for the simultaneous double treatment at higher concentrations, but only an additive effect was detected with the largest experimental concentrations used.

DZ-Nep + panobinostat combined treatment reduces cell clonogenicity of glioblastoma cells. The double treatment of DZ-Nep + panobinostat significantly decreased the number of colonies on plates $(\mathrm{P}<0.001)$ in T98G, LN405, LN405-TMZR, MOG-G-CCM, U87MG, A172 and A172-TMZR cells, and in PE9 primary tumor cells. The clonogenicity of PE8 cells was significantly reduced following exposure to each individual treatment with respect to the control; however, combined treatment was not significantly different to the individual treatments. In GOS3 cells, the individual treatments induced significant decreases in clonogenicity compared with the control; however, combined treatment was not significantly different to control treatment (Fig. 1).

In addition, combined treatment induced significantly greater clonogenic inhibition than that caused by the individual treatments (DZ-Nep or panobinostat) in A172, A172-TMZR, U87MG, LN405-TMZR and T98G cell lines 

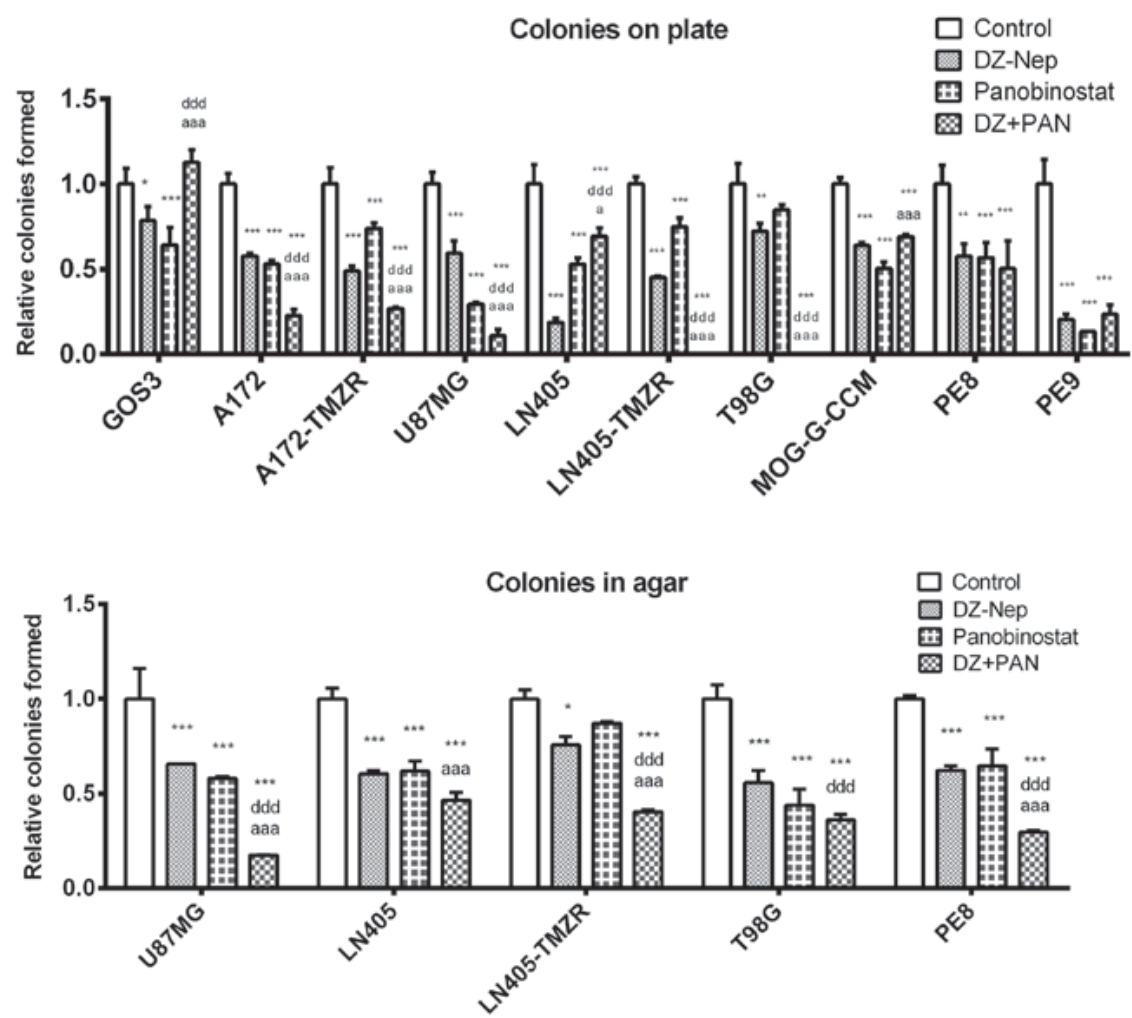

Figure 1. Colony formation capacity in adherent conditions or in soft agar following treatment with DZ-Nep, panobinostat or combined treatment. Data are presented as the mean \pm standard deviation of three independent repeats. All control values were normalized to $1 .{ }^{*} \mathrm{P}<0.05,{ }^{* * *} \mathrm{P}<0.01,{ }^{* * * *} \mathrm{P}<0.001 \mathrm{vs}$. control; ${ }_{\text {ddd }} \mathrm{P}<0.001$ vs. DZ-Nep; ${ }^{\text {aP }}<0.05$, ${ }^{\text {aaa }} \mathrm{P}<0.001$ vs. panobinostat (Tukey's test). DZ-Nep, 3-deazaneplanocin A; PAN, panobinostat.

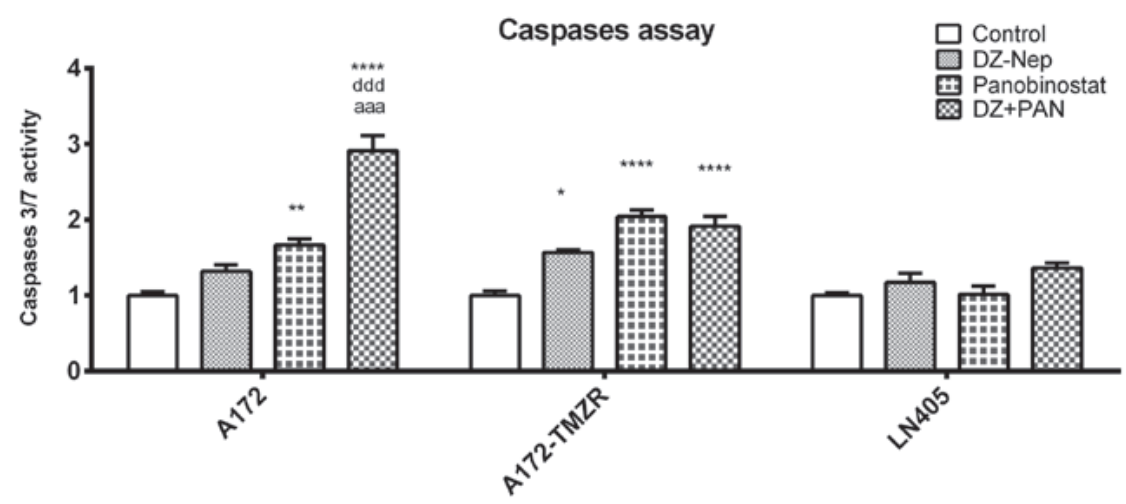

Figure 2. Activation of caspases 3/7 following treatment with DZ-Nep, panobinostat or combined treatment. Data are presented as the mean \pm standard deviation of three independent repeats. All control values were normalized to $1 .{ }^{*} \mathrm{P}<0.05,{ }^{* *} \mathrm{P}<0.01,{ }^{* * * * *} \mathrm{P}<0.0001$ vs. control; ${ }^{\text {ddd }} \mathrm{P}<0.001 \mathrm{vs}$. DZ-Nep; ${ }^{\text {aaa }} \mathrm{P}<0.001$ vs. panobinostat (Tukey's test). DZ-Nep, 3-deazaneplanocin A; PAN, panobinostat.

$(\mathrm{P}<0.001)$. Furthermore, LN405-TMZR and T98G cells did not form any colonies on plates following combined treatment. Of note, panobinostat individual treatment induced a greater inhibition in the formation of colonies on plates than DZ-Nep + panobinostat combined treatment in LN405 cells (Fig. 1). This is an unusual phenomenon not observed in the other cell lines; however, the genetic heterogeneity of cancer cells renders it possible. Therefore, more cells and primary cultures are required in further studies to obtain more consistent results. Studies on this topic are therefore open to future research.

In the soft agar clonogenicity test (Fig. S5), although the greatest inhibition of colony formation was observed after
DZ-Nep + panobinostat combined treatment in all cell lines $(\mathrm{P}<0.001)$, the inhibition induced by this treatment was significantly different to that induced by the two individual treatments (DZ-Nep or panobinostat) only in U87MG, LN405-TMZR and PE8 cells ( $\mathrm{P}<0.001 ;$ Fig. 1). In the LN405 and T98G cell lines, the double treatment induced a significantly greater inhibition than the inhibition caused by the treatment of DZ-Nep $(\mathrm{P}<0.001)$.

DZ-Nep + panobinostat combined treatment increases apoptosis of glioblastoma cells. The levels of activation of caspases 3 and 7 were measured in A172, A172-TMZR and LN405 cells after $2 \mathrm{~h}$ of individual treatment with DZ-Nep and panobinostat, and the simultaneous double treatment of 

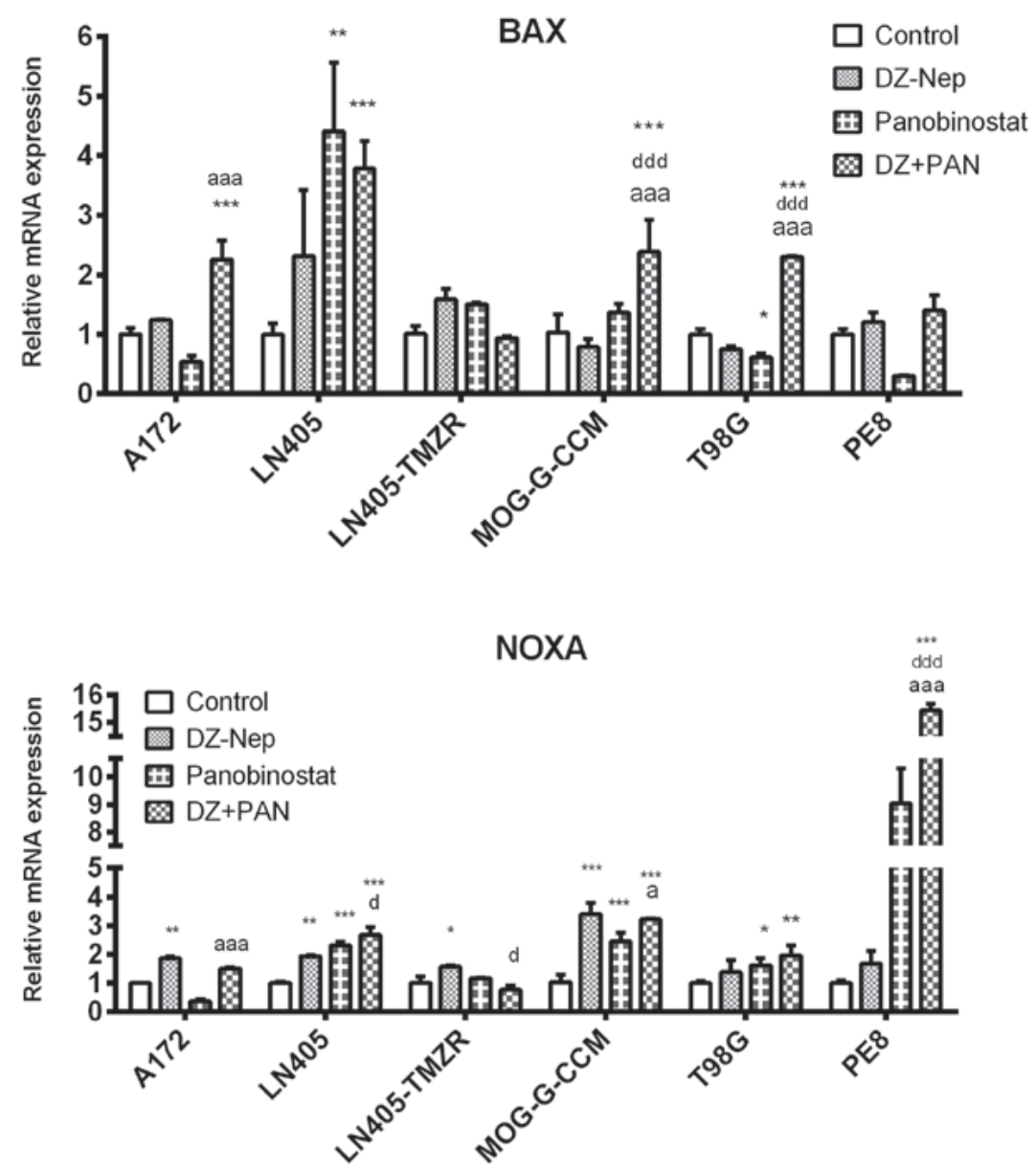

Figure 3. BAX and NOXA mRNA expression in cell lines treated for $72 \mathrm{~h}$ with DZ-Nep, panobinostat or a combination of both. Data are presented as the mean \pm standard deviation of three independent repeats. All control values were normalized to $1 .{ }^{*} \mathrm{P}<0.05,{ }^{* * *} \mathrm{P}<0.01,{ }^{* * * *} \mathrm{P}<0.001$ vs. control; ${ }^{\mathrm{d}} \mathrm{P}<0.05$, ddd $\mathrm{P}<0.001$ vs. DZ-Nep; ${ }^{\text {a }} \mathrm{P}<0.05$, aaa $\mathrm{P}<0.001$ vs. panobinostat (Tukey's test). DZ-Nep, 3-deazaneplanocin A; PAN, panobinostat.

DZ-Nep + panobinostat (Fig. 2). Double treatment produced a significant activation of caspases in A172 and A172-TMZR cells $(\mathrm{P}<0.001)$. Double treatment produced a significant increase in activated caspases in A172 cells, but not in A172-TMZR cells, with respect to individual treatments; similar values were produced in A172-TMZR cells after either double treatment or panobinostat individual treatment. No significant caspase activation was observed in LN405 cells.

The combination of DZ-Nep + panobinostat significantly increased BAX expression in A172, LN405, MOG-G-CCM and T98G cells $(\mathrm{P}<0.001$; Fig. 3). The increase produced by combined treatment in MOG-G-CCM and T98G cells was significantly greater than that induced by the individual treatments of DZ-Nep or panobinostat $(\mathrm{P}<0.001)$.

These changes were similar to those observed in the expression of NOXA produced by the combined treatment of DZ-Nep + panobinostat, where it was found that the double treatment increased the expression of NOXA in T98G $(\mathrm{P}<0.01)$ and in LN405, MOG-G-CCM and PE8 cells ( $\mathrm{P}<0.001$; Fig. 3). The greatest increase in NOXA was detected in PE8 cells, significantly higher in the double treatment compared with the individual treatments (both $\mathrm{P}<0.001$ ).

The combination of DZ-Nep + panobinostat significantly decreased the expression of the BCL-2 antiapoptotic gene in MOG-G-CCM, T98G and PE8 cells $(\mathrm{P}<0.001)$. Lines A172,
LN405 and LN405-TMZR showed significant increases in BCL-2 expression ( $\mathrm{P}<0.001$; Fig. 4).

The double treatment of DZ-Nep + panobinostat significantly increased the expression of BCL-XL in LN405 and MOG-G-CCM ( $\mathrm{P}<0.001)$, and PE8 cells $(\mathrm{P}<0.05$; Fig. 4).

\section{DZ-Nep + temozolomide combined treatment}

DZ-Nep + temozolomide combined treatment shows a synergistic effect at the highest concentrations. The combination of DZ-Nep + temozolomide used did not result in any Fa>0.5 (Table SIV). A synergistic effect appeared after $72 \mathrm{~h}$ combined treatment for LN405 cells. Compusyn predictions indicated a clear synergy in the combined treatments of DZ-Nep + temozolomide, and in the pre-treatment of temozolomide followed by post-treatment with DZ-Nep in GOS-3, MOG-G-CCM and LN405 cells. LN405 and LN405-TMZR cells were predicted to have synergy in the pre-treatment of DZ-Nep followed by post-treatment of temozolomide; this treatment did not prove to be effective in the other cell lines. U87MG cells exhibited clear antagonism in all treatments with these two drugs. The CI values obtained were plotted logarithmically in Fig. S6.

DZ-Nep + temozolomide combined treatment specifically inhibits clonogenicity of temozolomide-sensitive cells. The double treatment of DZ-Nep + temozolomide significantly decreased the number of colonies on plates $(\mathrm{P}<0.001$; Fig. 5) 

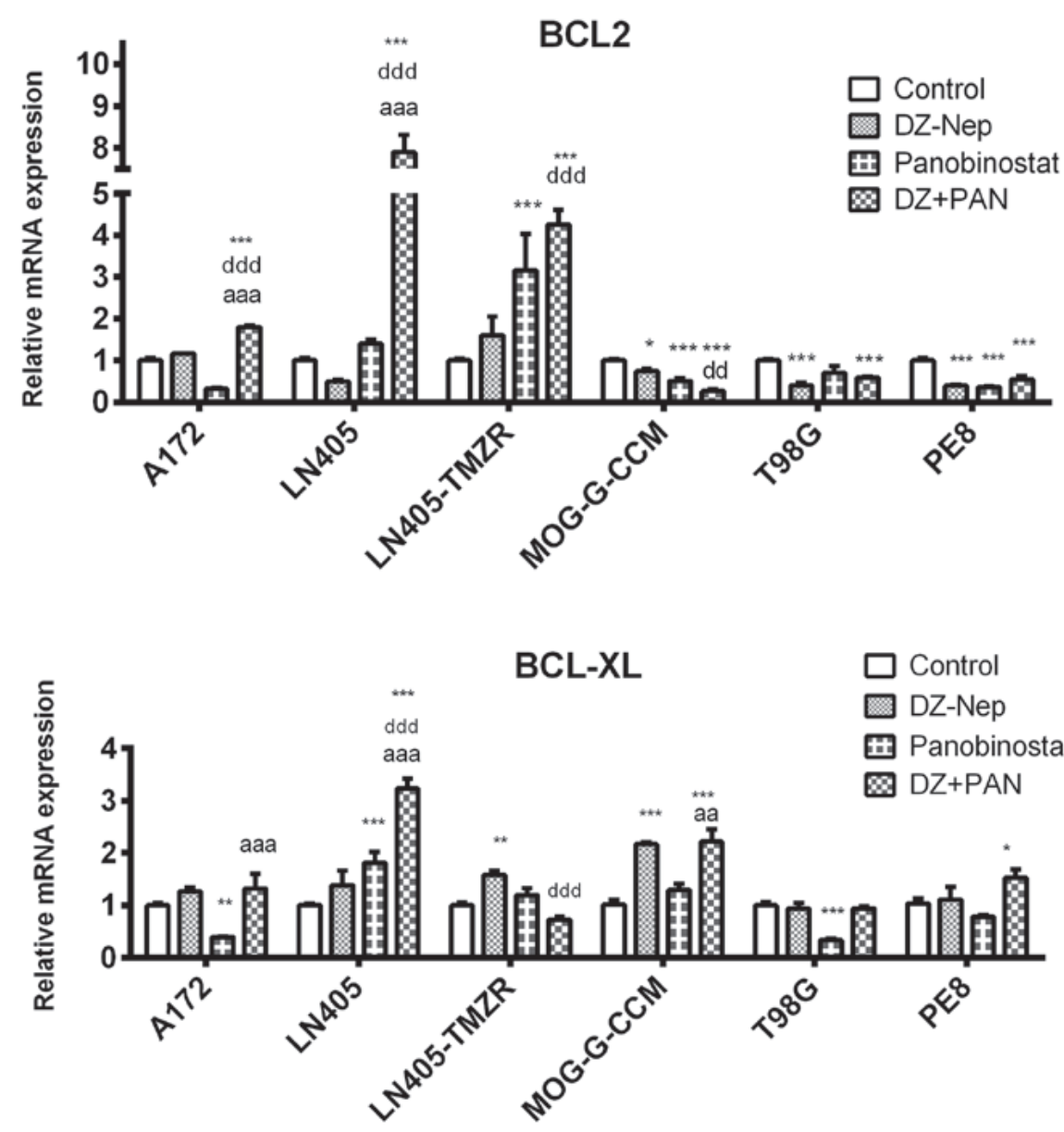

Figure 4. BCL-2 and BCL-XL mRNA expression in cell lines treated for $72 \mathrm{~h}$ with DZ-Nep, panobinostat or a combination of both. Data are presented as the mean \pm standard deviation of three independent repeats. All control values were normalized to $1 .{ }^{*} \mathrm{P}<0.05,{ }^{* *} \mathrm{P}<0.01,{ }^{* * * *} \mathrm{P}<0.001$ vs. control; ${ }^{\text {dd }} \mathrm{P}<0.01,{ }^{\text {ddd }} \mathrm{P}<0.001$ vs. DZ-Nep; ${ }^{\text {aa }} \mathrm{P}<0.01,{ }^{\text {aaa }} \mathrm{P}<0.001$ vs. panobinostat (Tukey's test). DZ-Nep, 3-deazaneplanocin A; PAN, panobinostat.

in A172, A172-TMZR, U87MG, T98G, MOG-G-CCM, PE8 and PE9 cells. This treatment did not show significant changes with respect to the control treatment in GOS-3, LN405 and LN405-TMZR cells.

The double treatment of DZ-Nep + temozolomide induced significantly greater inhibition compared with that produced by the two individual treatments in A172, U87MG, and PE9 cells, which exhibited lower resistance to temozolomide than the rest of the cells in the present study (Fig. 5).

These findings were further validated using the clonogenicity experiment in anchoring independent conditions (Fig. S5) when seeding the treated cells in soft agar. Only the U87MG line showed significantly greater inhibition induced by the double treatment of DZ-Nep + temozolomide compared with that caused by the two individual treatments $(\mathrm{P}<0.001)$. In LN405 and LN405-TMZR cells, which are more resistant to temozolomide, no differences were observed between the double treatment and the individual treatments of DZ-Nep and temozolomide (Fig. 5). In addition, T98G showed a significant difference $(\mathrm{P}<0.001)$ between the combined treatment and individual treatment of DZ-NEP only.

DZ-Nep + temozolomide combined treatment partially increases apoptosis of glioblastoma cells. The levels of caspase activation in A172, A172-TMZR, and LN405 cells was studied after $2 \mathrm{~h}$ of individual treatment with DZ-Nep or temozolomide, and simultaneous double treatment of
DZ-Nep + temozolomide (Fig. 6). Double treatment produced a significant activation of caspases in A172 cells compared with the control treatment $(\mathrm{P}<0.0001)$ and $\mathrm{DZ}-\mathrm{Nep}$ individual treatment $(\mathrm{P}<0.05)$. The double treatment did not produce a significant increase in caspase activation in A172-TMZR and LN405 cells.

DZ-Nep + temozolomide combined treatment significantly increased BAX expression (Fig. 7) in A172, LN405, LN405-TMZR, MOG-G-CCM and PE8 cells ( $\mathrm{P}<0.01)$. It also produced a significant increase of NOXA expression (Fig. 7) in these cell lines $(\mathrm{P}<0.01$ for LN405-TMZR; $\mathrm{P}<0.001$ for all other cells). In MOG-G-CCM, LN405-TMZR and T98G cells, however, double treatment did not produce a significantly greater increase in NOXA expression than that produced by the individual treatment of DZ-Nep. Double treatment did not significantly increase the levels of BAX or NOXA in T98G cells compared with control.

Simultaneous double treatment of DZ-Nep + temozolomide significantly increased the expression of BCL-2 antiapoptotic gene in LN405 $(\mathrm{P}<0.01)$, LN405-TMZR $(\mathrm{P}<0.05)$ and MOG-G-CCM $(\mathrm{P}<0.001)$ cells compared with the control. A172, T98G and PE8 cells did not show significant differences in BCL-2 expression levels after this treatment (Fig. 8).

Double treatment of DZ-Nep + temozolomide strongly significantly decreased the expression of the antiapoptotic gene BCL-XL in T98G cells $(\mathrm{P}<0.001)$. However, a highly 

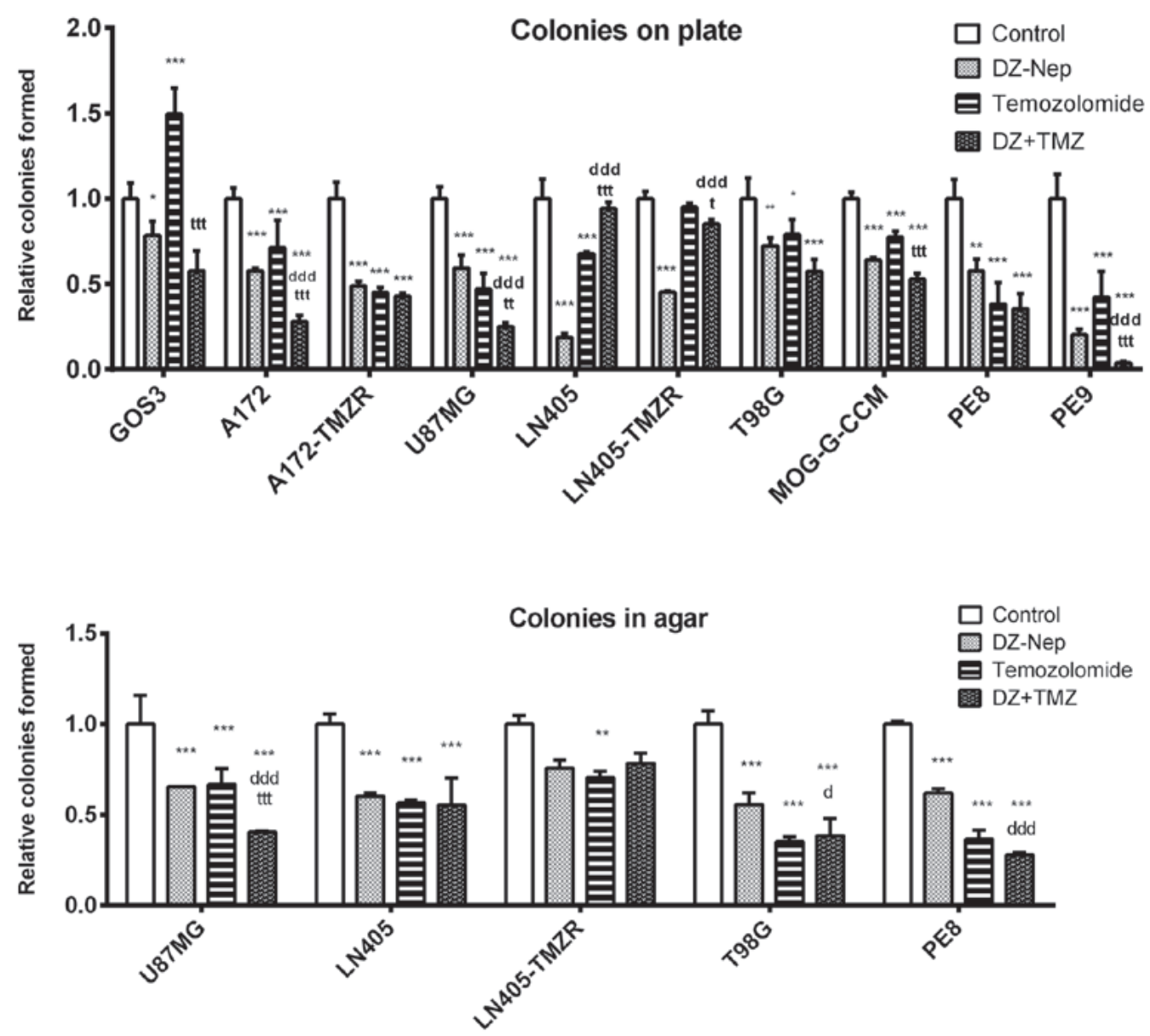

Figure 5. Colony formation capacity in adherent conditions or in soft agar following treatment with DZ-Nep, temozolomide or combined treatment. Data are presented as the mean \pm standard deviation of three independent repeats. All control values were normalized to $1 .{ }^{*} \mathrm{P}<0.05,{ }^{* * *} \mathrm{P}<0.01,{ }^{* * * *} \mathrm{P}<0.001 \mathrm{vs}$. control; ${ }_{\text {ddd }} \mathrm{P}<0.001$ vs. DZ-Nep; ${ }^{\mathrm{P}}<0.05$, ${ }^{\text {tt}} \mathrm{P}<0.01$, ${ }^{\text {ttP}} \mathrm{P}<0.001$ vs. temozolomide (Tukey's test). DZ-Nep, 3-deazaneplanocin A; TMZ, temozolomide.

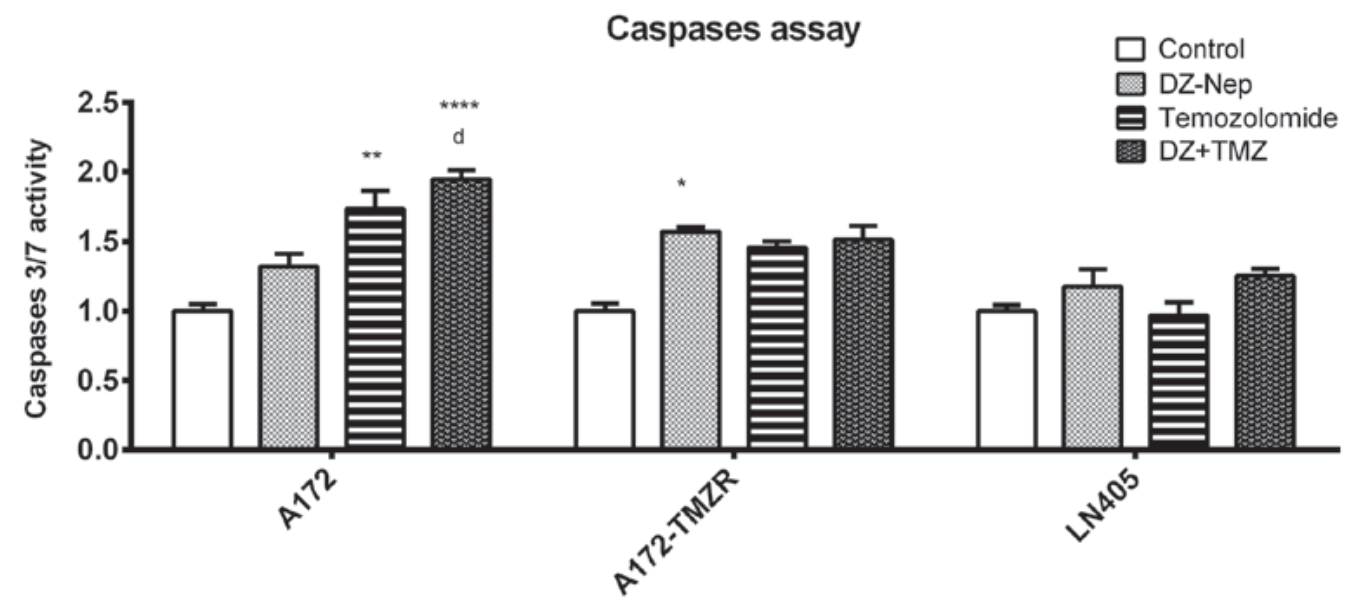

Figure 6. Activation of caspases 3/7 following treatment with DZ-Nep, temozolomide or combined treatment. Data are presented as the mean \pm standard deviation of three independent repeats. All control values were normalized to $1 .{ }^{*} \mathrm{P}<0.05,{ }^{* *} \mathrm{P}<0.01,{ }^{* * * *} \mathrm{P}<0.0001$ vs. control; ${ }^{\mathrm{d}} \mathrm{P}<0.05$ vs. DZ-Nep (Tukey's test). DZ-Nep, 3-deazaneplanocin A; TMZ, temozolomide.

significant increase in BCL-XL was detected in the remaining the cell lines studied $(\mathrm{P}<0.001$; Fig. 8).

Panobinostat + temozolomide combined treatment

Panobinostat + temozolomide combined treatment shows a synergistic effect. The CI values obtained mostly showed antagonism for the smallest Fa values, and synergy for the highest Fa (Table SV). In particular, U87MG cells showed higher CI indexes in the simultaneous 72-h (P72T72) double treatment and in the pre-treatment of temozolomide followed by panobinostat. Temozolomide pre-treatment/panobinostat post-treatment (T24P48) was also generally effective against 

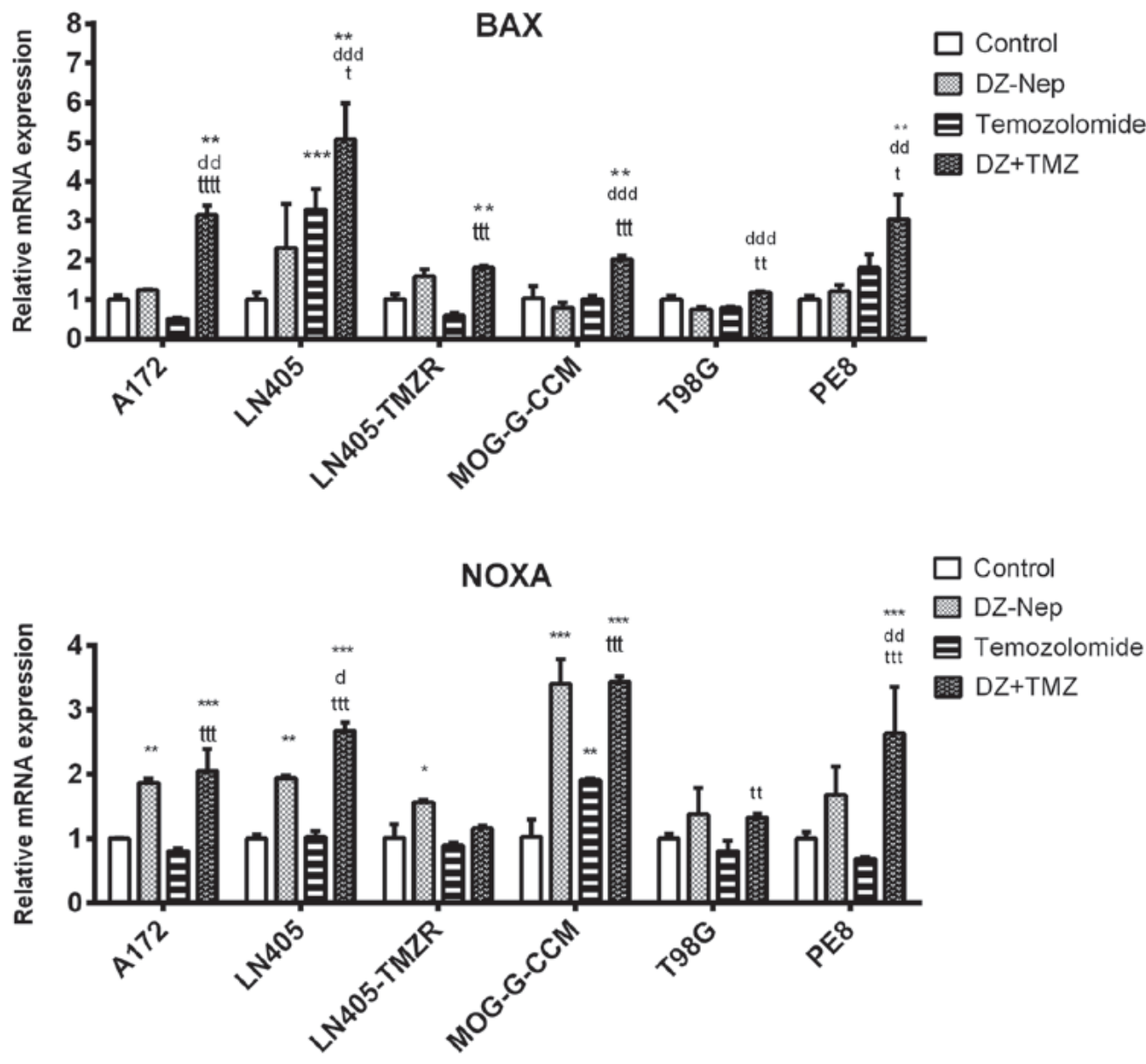

Figure 7. BAX and NOXA mRNA expression in cell lines treated for $72 \mathrm{~h}$ with DZ-Nep, temozolomide or a combination of both. Data are presented as the mean \pm standard deviation of three independent repeats. All control values were normalized to $1 .{ }^{*} \mathrm{P}<0.05 ;{ }^{* * *} \mathrm{P}<0.01,{ }^{* * * *} \mathrm{P}<0.001$ vs. control; ${ }^{d} \mathrm{P}<0.05$, ${ }^{\text {dd }} \mathrm{P}<0.01$, ${ }^{\text {ddd }} \mathrm{P}<0.001$ vs. DZ-Nep; ${ }^{\mathrm{P}}<0.05,{ }^{\text {t }} \mathrm{P}<0.01,{ }^{\text {tt }} \mathrm{P}<0.001,{ }^{\text {tttt }} \mathrm{P}<0.0001$ vs. temozolomide (Tukey's test). DZ-Nep, 3-deazaneplanocin A; TMZ, temozolomide.

GOS-3 cells, and only at the highest concentrations in MOG-G-CCM, LN405 and LN405-TMZR cells.

LN405 cells revealed a synergistic or additive effect following double treatment, whereas its temozolomide-resistant variant, the LN405-TMZR line, showed lower synergy and $\mathrm{Fa}$ at low concentrations, although synergy and the $\mathrm{Fa}$ increased at higher concentrations of treatment. Synergistic estimates predicted by Compusyn revealed a clear synergy of T24P48 treatment in all cell lines, and a clear synergy in the P72T72 treatment in almost all cell lines, with the exception of LN405. Synergy was only predicted for the pre-treatment of panobinostat followed by a post-treatment of temozolomide in GOS-3, LN405 and LN405-TMZR cells. The logarithms of the CIs were represented in Fig. S7.

Panobinostat + temozolomide combined treatment effectively inhibits the clonogenic potential of cell lines. The double treatment of panobinostat + temozolomide significantly decreased the number of colonies on plate in all cell lines studied $(\mathrm{P}<0.001)$. Significant differences were observed between the inhibition caused by the double treatment and by the individual treatments of panobinostat or temozolomide in GOS-3, A172-TMZR, LN405 and LN405-TMZR cells (Fig. 9). In addition, the inhibition of clonogenicity observed in LN405-TMZR following double treatment of panobinostat + temozolomide appeared to be markedly greater than that in LN405.
A soft agar clonogenicity experiment (Fig. S5) confirmed this result. The double treatment of panobinostat + temozolomide showed a significantly higher inhibition of clonogenicity than the two individual treatments of panobinostat or temozolomide in U87MG and LN405 cells $(\mathrm{P}<0.001)$. No differences were found between the double treatment and the individual treatment of temozolomide in T98G and PE8 cells. Finally, the double treatment showed an antagonistic effect, with a significant increase in the number of colonies formed in agar, in LN405-TMZR cells ( $\mathrm{P}<0.05$; Fig. 9).

Panobinostat + temozolomide combined treatment increases the apoptosis of glioblastoma cells. The levels of caspase activation in A172, A172-TMZR and LN405 cells were studied after $2 \mathrm{~h}$ of individual treatment with panobinostat or temozolomide, and simultaneous double treatment of panobinostat + temozolomide (Fig. 10). Double treatment significantly increased caspase activity in A172 and A172-TMZR cells compared with the control treatment $(\mathrm{P}<0.0001)$, or individual treatment with temozolomide $(\mathrm{P}<0.0001)$. The levels of activated caspases induced by double treatment was significantly greater than those induced by individual treatment with panobinostat in A172 cells $(\mathrm{P}<0.0001)$. No treatment produced a significant increase of activated caspases in LN405 cells.

Double treatment of panobinostat + temozolomide significantly increased the expression of BAX and NOXA (Fig. 11) 

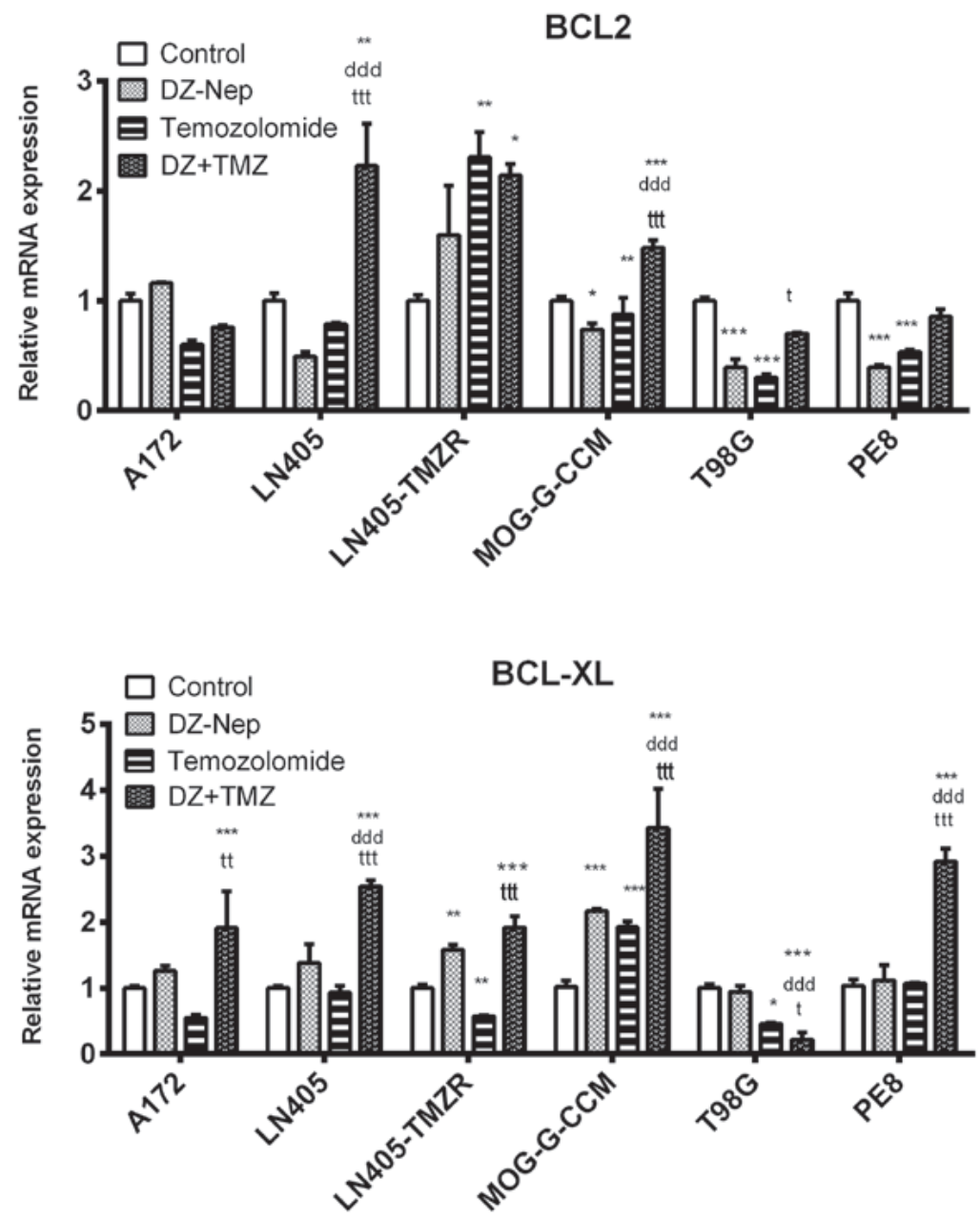

Figure 8. BCL-2 and BCL-XL mRNA expression in cell lines treated for $72 \mathrm{~h}$ with DZ-Nep, temozolomide or a combination of both. Data are presented as the mean \pm standard deviation of three independent repeats. All control values were normalized to $1 .{ }^{*} \mathrm{P}<0.05 ;{ }^{* *} \mathrm{P}<0.01,{ }^{* * *} \mathrm{P}<0.001 \mathrm{vs}$. control; ${ }^{\text {dd }} \mathrm{dP}<0.001$ vs. DZ-Nep; ${ }^{\mathrm{P}}<0.05$, ${ }^{\text {tt}} \mathrm{P}<0.01$, ${ }^{\text {ttP }} \mathrm{P}<0.001$ vs. temozolomide (Tukey's test). DZ-Nep, 3-deazaneplanocin A; TMZ, temozolomide.

in LN405, MOG-G-CCM and PE8 cells compared with the control $(\mathrm{P}<0.001)$. A significant increase of $\mathrm{BAX}$ in $\mathrm{A} 172$ cells $(\mathrm{P}<0.001)$ and of NOXA in T98G cells $(\mathrm{P}<0.001)$ was detected in the other cell types. LN405-TMZR cells exhibited no significant changes in the expression of either proapoptotic gene.

Panobinostat + temozolomide combined treatment significantly decreased the expression of BCL-2 in A172 and PE8 cells compared with the control $(\mathrm{P}<0.001)$. In LN405, LN405-TMZR and T98G cells, however, double treatment increased BCL-2 expression (Fig. 12).

Combined panobinostat + temozolomide treatment strongly significantly decreased the expression of the antiapoptotic gene BCL-XL in T98G cells $(\mathrm{P}<0.001)$. Conversely, the expression of BCL-XL was significantly upregulated in LN405 and MOG-G-CCM cells ( $<<0.001$; Fig. 12).

DZ-Nep + panobinostat + temozolomide triple combination . The triple combination of DZ-Nep + panobinostat + temozolomide resulted in high synergistic CI indexes in all cell lines (Table SVI and Fig. S8).

Although GOS-3 and LN405-TMZR cells showed antagonism when working with drug concentrations that produced a small Fa, these drugs showed a synergistic effect at the concentrations corresponding to bigger Fa values, data confirmed by the Compusyn predictions. Although a greater effect was observed in LN405 compared withLN405-TMZR cells, Compusyn predicted higher synergistic results at the highest Fa for LN405-TMZR cells than for LN405 cells.

\section{Discussion}

In response to combined DZ-Nep and panobinostat treatment, Compusyn predicted a synergistic response in the cell lines used, with the exception of LN405 and LN405-TMZR cells, where additive and antagonistic responses were obtained, respectively. Consistent with these predictions, significant increases in BAX and NOXA expression levels were not observed in LN405-TMZR cells, in contrast to the other cell lines. DZ-Nep + panobinostat combined treatment effectively inhibited the formation of colonies on agar in the analyzed cell lines. As two agents that inhibit gene expression at different epigenetic levels (DZ-Nep affects EZH2, panobinostat affects HDACs), it is not surprising that their combination is highly effective, as previously described (52-54). Therefore, DZ-Nep + panobinostat may represent a promising drug combination in the treatment of brain tumors. It is probable that the inhibition of EZH2 induced by DZ-Nep facilitates 

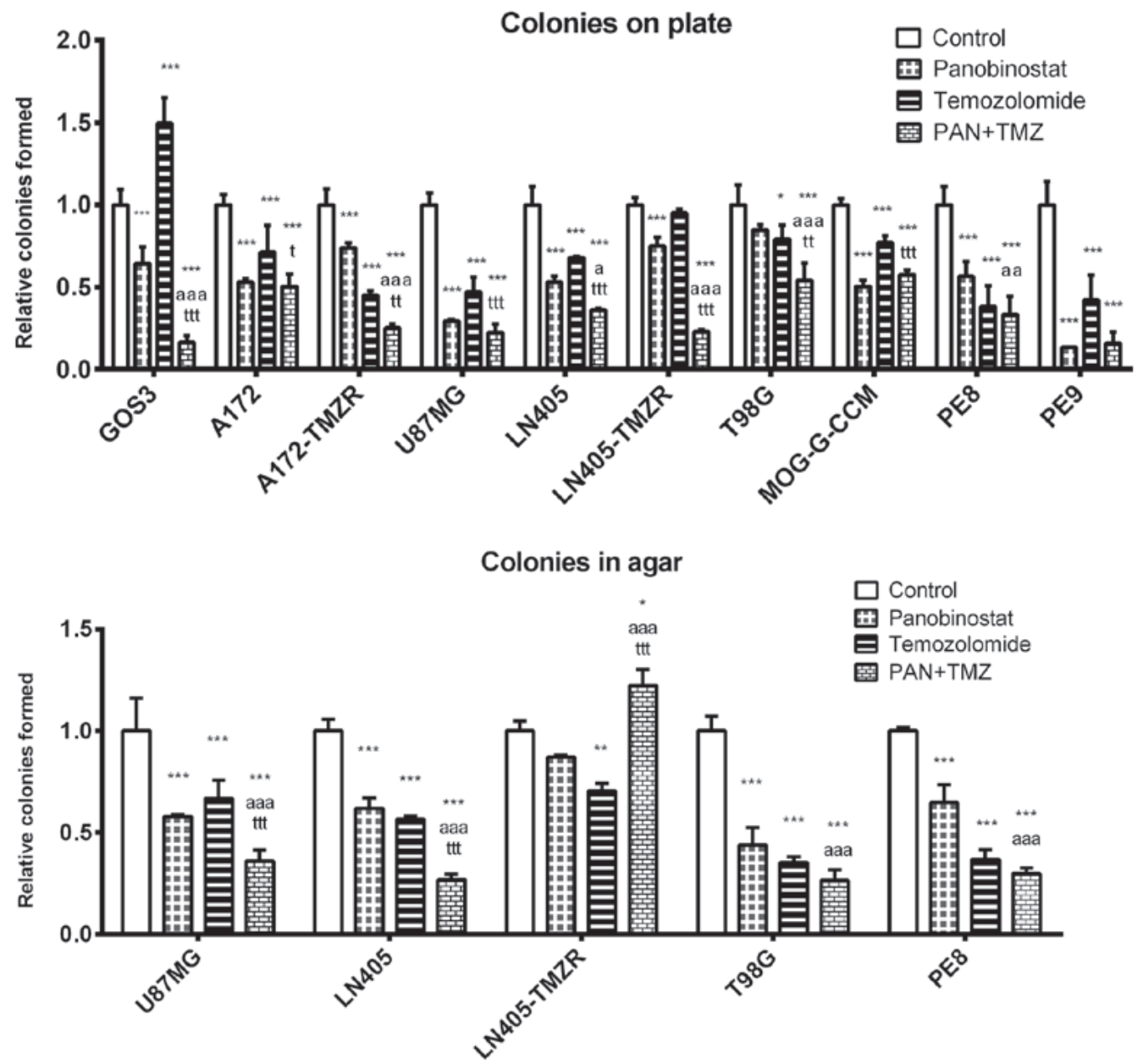

Figure 9. Colony formation capacity in adherent conditions or in soft agar following treatment with panobinostat, temozolomide or combined treatment. Data are presented as the mean \pm standard deviation of three independent repeats. All control values were normalized to $1 .{ }^{*} \mathrm{P}<0.05 ;{ }^{* *} \mathrm{P}<0.01,{ }^{* * * *} \mathrm{P}<0.001$ vs. control; ${ }^{\text {a }} \mathrm{P}<0.05$, ${ }^{\text {aa }} \mathrm{P}<0.01$, ${ }^{\text {aaa }} \mathrm{P}<0.001$ vs. panobinostat; ${ }^{\mathrm{P}}<0.05$, ${ }^{\text {tP}} \mathrm{P}<0.01$, ${ }^{\text {tt }} \mathrm{P}<0.001$ vs. temozolomide (Tukey's test). PAN, panobinostat; TMZ, temozolomide.

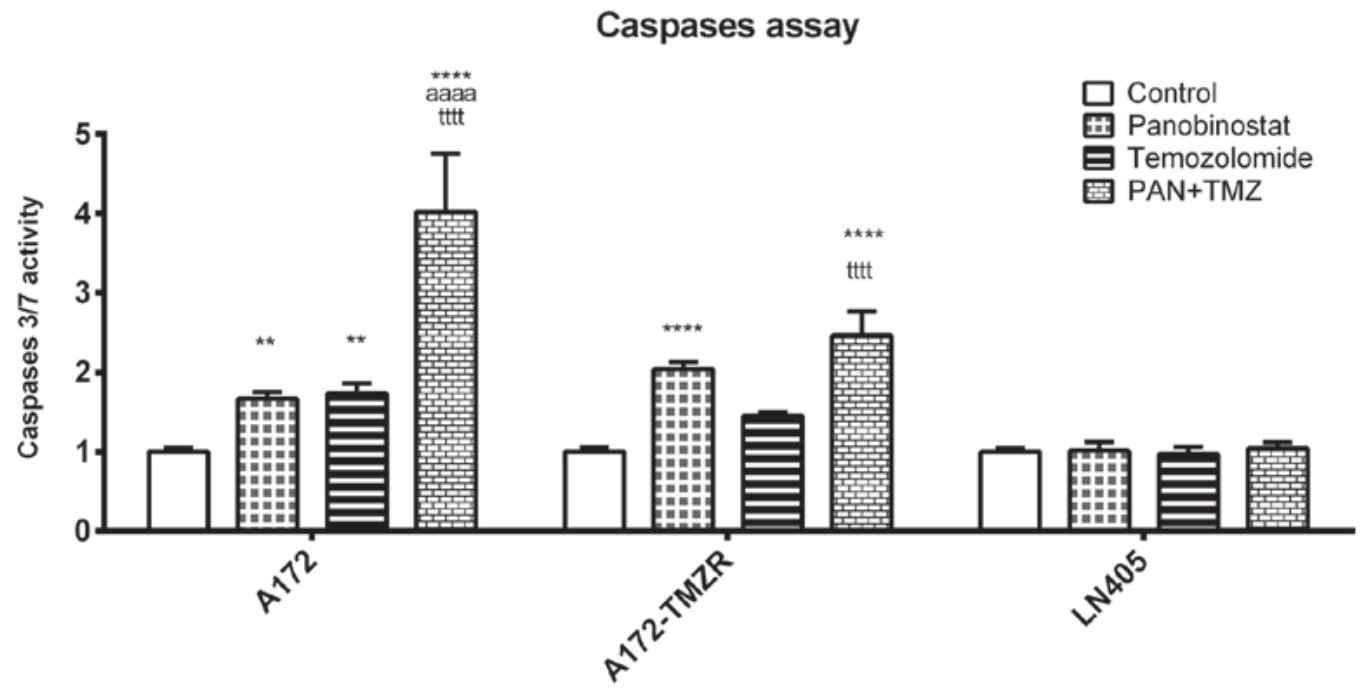

Figure 10. Activation of caspases 3/7 following treatment with panobinostat, temozolomide or combined treatment. Data are presented as the mean \pm standard deviation of three independent repeats. All control values were normalized to $1 .{ }^{* *} \mathrm{P}<0.01,{ }^{* * * * *} \mathrm{P}<0.0001$ vs. control; ${ }^{\text {aaaaa }} \mathrm{P}<0.0001$ vs. panobinostat; ${ }^{\text {tttt }} \mathrm{P}<0.0001$ vs. temozolomide (Tukey's test). PAN, panobinostat; TMZ, temozolomide.

demethylation of $\mathrm{H} 2 \mathrm{~K} 27 \mathrm{me} 3$. The absence of methylation would favor subsequent histone acetylation by histone acetyl- transferases (55) following the H3K27me3 to H3K27Ac switch on chromatin. Panobinostat, by inhibiting the deacetylation 

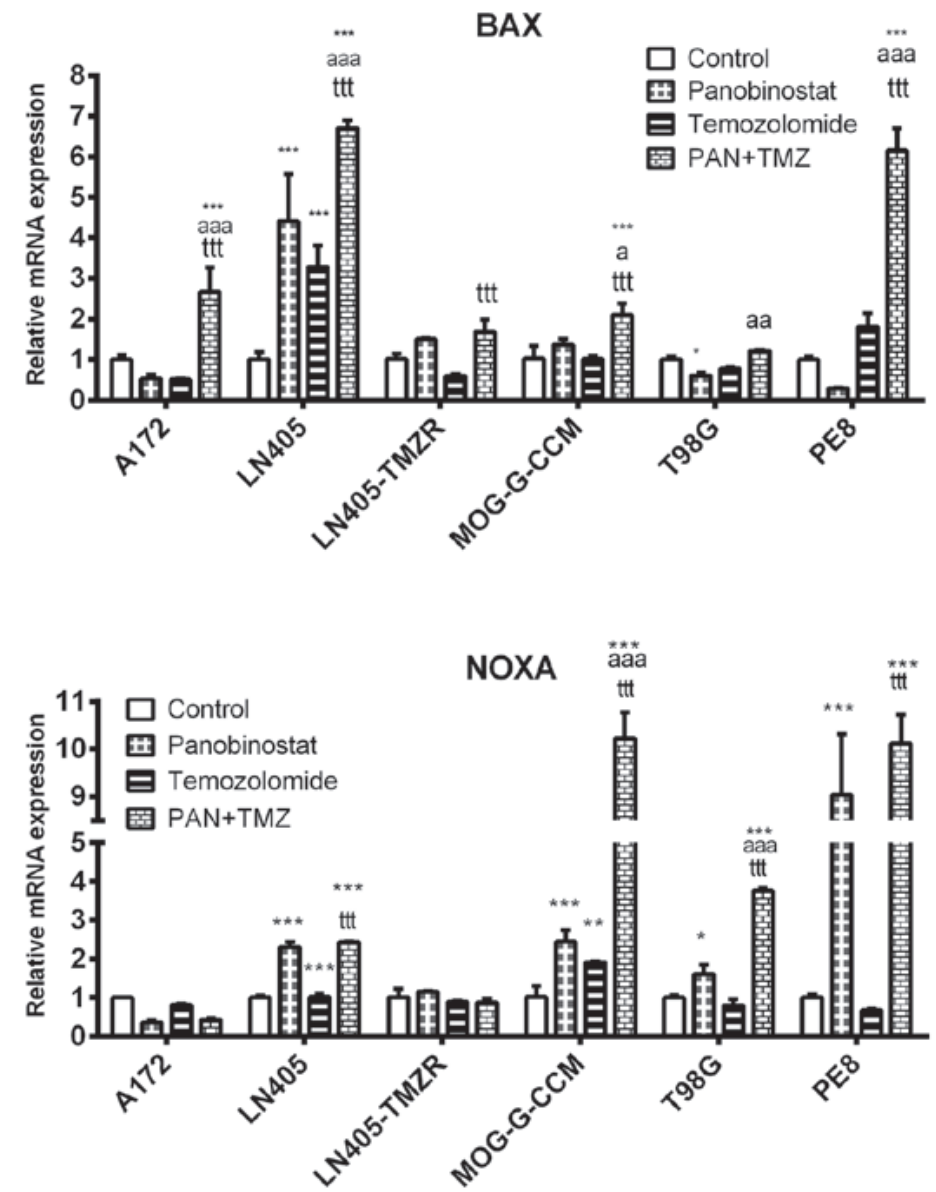

Figure 11. BAX and NOXA mRNA expression in cell lines treated for $72 \mathrm{~h}$ with panobinostat, temozolomide or a combination of both. Data are presented as the mean \pm standard deviation of three independent repeats. All control values were normalized to $1 .{ }^{*} \mathrm{P}<0.05,{ }^{* * *} \mathrm{P}<0.01,{ }^{* * *} \mathrm{P}<0.001$ vs. control; ${ }^{\text {a }} \mathrm{P}<0.05$, ${ }^{\text {aa }} \mathrm{P}<0.01$, ${ }^{\text {aaa }} \mathrm{P}<0.001$ vs. panobinostat; "tt $\mathrm{P}<0.001$ vs. temozolomide (Tukey's test). PAN, panobinostat; TMZ, temozolomide.

induced by several HDACs, would help to maintain histone acetylation. All this would facilitate the apoptosis of malignant cells through multiple signaling pathways.

The studied combinations of DZ-Nep + temozolomide did not result in a very high $\mathrm{Fa}$ in the studied cell lines, although the predictions made by Compusyn for higher Fa values generally indicated a synergistic behavior, except in U87MG and LN405-TMZR cells, where antagonistic behavior was predicted. DZ-Nep and temozolomide are not compounds that induce rapid apoptotic responses in cells. DZ-Nep typically requires long incubation times, and temozolomide usually causes cell cycle arrest (56) or cell senescence (57). These reasons complicate the analysis of the synergistic effect according to the CI method used in this study. Although the results obtained suggest the existence of synergy between these two compounds, it is necessary to use longer incubation times to establish whether these combined drugs behave according to an additive, synergistic or antagonistic model.

The combination of these two drugs only produced greater inhibition of agar colony formation than treatment with the individual drugs in U87MG cells. In parallel, there was a greater inhibition in the formation of colonies on plates in A172, U87MG and PE9 cells. The cells presenting the highest resistance to temozolomide (GOS-3, LN405, LN405-TMZR, T98G and MOG-G-CCM) did not appear to be more sensitive to the combination of drugs compared with the two indi- vidual drugs. All these lines carry p53 mutations (Table I). It is possible that the dose of temozolomide used was not high enough to induce significant effects in these cell lines, and synergy was not achieved when working with low drug concentrations in these types of experiments. Conversely, the expression of the proapoptotic genes BAX and NOXA was increased in all cell lines. The increase observed in LN405-TMZR cells was lower compared with that in LN405 cells. This increase in apoptosis may encourage future studies into this therapeutic combination.

For panobinostat + temozolomide co-treatment, Compusyn again predicted a highly synergistic response with high $\mathrm{Fa}$ values, except in LN405 cells. Of note, LN405-TMZR cells appeared to be more sensitive to this combination than LN405 cells, with larger Fa values and a more synergistic response predicted by Compusyn. The accumulated DNA damage tolerated by LN405-TMZR cells may reduce the threshold of response to damage induced by combined treatment with panobinostat + temozolomide, explaining its greater sensitivity to this therapeutic combination compared with LN405 cells.

This combination of drugs produced the greatest inhibition in the formation of colonies on plates in all cell lines, and also the greatest inhibition in the formation of soft agar colonies in all cell lines except in LN405-TMZR. A similar increase in the expression levels of proapoptotic genes was observed in almost all cell lines, which makes the combina- 

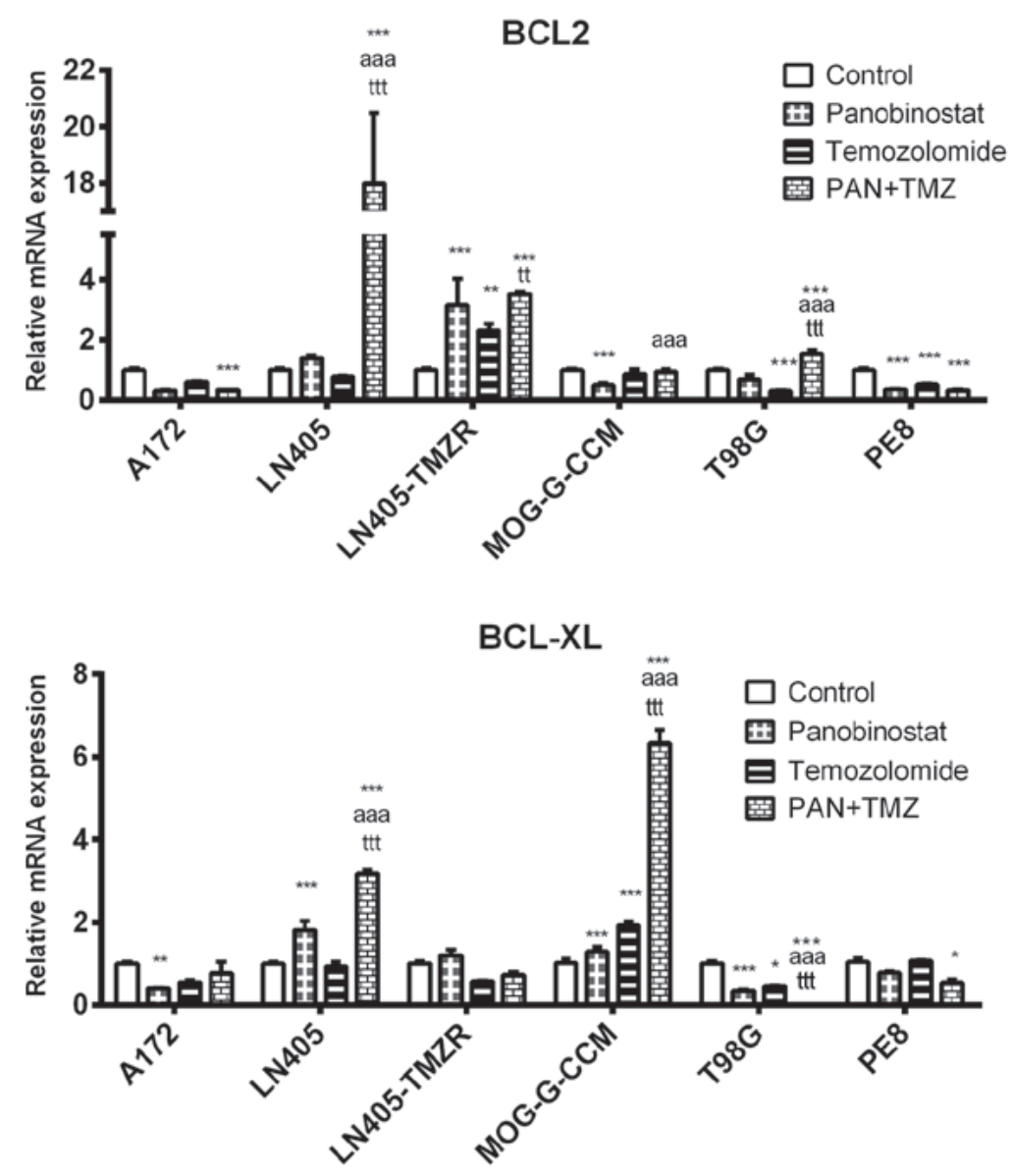

Figure 12. BCL-2 and BCL-XL mRNA expression in cell lines treated for $72 \mathrm{~h}$ with panobinostat, temozolomide or a combination of both. Data are presented as the mean \pm standard deviation of three independent repeats. All control values were normalized to $1 .{ }^{*} \mathrm{P}<0.05,{ }^{* *} \mathrm{P}<0.01,{ }^{* * * *} \mathrm{P}<0.001$ vs. control; aaa $\mathrm{P}<0.001$ vs. panobinostat; ${ }^{\text {tt}} \mathrm{P}<0.01,{ }^{\text {ttP }}<0.001$ vs. temozolomide (Tukey's test). PAN, panobinostat; TMZ, temozolomide.

tion of panobinostat + temozolomide a potential candidate for future research into the development of novel therapies against glioblastoma.

Combinatorial studies were also conducted to evaluate the synergy of the DZ-Nep + temozolomide + panobinostat triple combination. When evaluating the synergy of a group of $\geq 3$ drugs, it should be understood that an increase in cellular effects is not necessarily dependent upon the synergistic behavior of all the compounds present in the therapeutic mixture; rather it is enough that two of these compounds are synergistic to observe a greater effect. To avoid these potential confusions, it was decided to use the drugs at very low concentrations, corresponding to one third of the concentrations used in the combinatorial experiments of drug pairs. In this range of concentrations, no drug pair should produce a high $\mathrm{Fa}$. Therefore, if a high $\mathrm{Fa}$ is produced by a triple combination of drugs, it can be concluded that the synergy was generated by the three drugs.

The combination of DZ-Nep + panobinostat + temozolomide was found to be highly synergistic, particularly at the highest concentrations. As a combination that includes DZ-Nep + temozolomide (the pair of drugs whose synergy is more questionable), this therapy showed high Fa values and very low $\mathrm{CI}$ indexes.

These triple combinations of drugs may be used as a therapeutic cocktail against glioblastoma with clinically relevant efficacy in future. It is necessary to conduct further in vivo experiments, however, to support any firmer conclusions regarding the clinical use of this therapeutic regimen.

If deciding which of the combinations of the different drugs is more effective, it may be hypothesized, observing the $\mathrm{CI}$ indices, that the panobinostat + temozolomide combination was the most synergistic (36 results of synergy), followed by the combination of DZ-Nep + panobinostat (20 synergistic results), and then the combination of DZ-Nep + temozolomide (10 synergistic results). Certainly, the triple treatment was more synergistic than the double treatments, as it produced synergy in 25 of the 30 experimental conditions; however, the experimental conditions for the triple treatment were not as broad as those used with the combinations of two drugs.

A second question is related to the genotype of the cell lines. In this sense, the following can be concluded: The greatest synergistic activity occurred in lines that carried p53 and/or PTEN mutations. When neither p53 nor PTEN were mutated (in the case of GOS-3), there was limited synergy in any pharmacological conditions. The DZ-Nep + panobinostat combination showed the highest synergy in the U87MG (mutated PTEN) and MOG-G-CCM (mutated p53) cell lines. The combination of panobinostat + temozolomide showed the highest synergy in the U87MG (mutated PTEN) and in LN405 (mutated PTEN and mutated p53) cell lines. Finally, the combination of DZ-Nep + temozolomide showed 
the highest synergy in the LN405 cell line (mutated PTEN and mutated p53). Conversely, the LN405-TMZR cell line, resistant to temozolomide, and also carrying PTEN and p53 mutations, did not exhibit similarly high occurrences of synergy compared with the aforementioned cell lines. When comparing the response of LN405 and LN405-TMZR to the different combinations of drugs, it was observed that the DZ-Nep + temozolomide combination was highly synergistic in LN405 cells (in five conditions) and less synergistic in LN405-TMZR (only one condition, with low Fa). The combination of panobinostat + temozolomide reduced the synergistic activity in the temozolomide-resistant cells; LN405 produced three synergistic conditions, and LN405-TMZR produced two synergistic conditions, although the $\mathrm{Fa}$ was higher in one of the conditions in LN405-TMZR. Finally, the DZ-Nep + panobinostat combination presented only one synergistic condition in both LN405 and LN405-TMZR, although in the latter, the Fa was greater.

Resistance to temozolomide, a phenomenon induced in the present study and a relevant to clinical settings (58), is a novel challenge to be investigated. Therefore, it appears necessary to conduct further studies in pharmacological synergy with more cell lines, both sensitive and resistant to temozolomide. Ideally, the genetic and epigenetic profiles of these cell lines should be known, in order to determine any possible association between the genetic and/or epigenetic status of the cell lines, and tumor resistance to temozolomide. However, in any case, it should be emphasized that the present work does not pretend to introduce these compounds into a clinical setting, so much as test them together to demonstrate that epigenetic treatments can synergistically combine with temozolomide treatment. Although multidrug combinations can theoretically promote increased cancer cell death, it can also result in more obvious side effects, such as granulocytopenia and thrombocytopenia, if applied to the chemotherapy of patients with glioma (59).

Further in vivo experiments would be of great benefit, but would go beyond the scope of this manuscript. Indeed, although assuming that not presenting in vivo data in the present manuscript is a limitation of the study, from the observed findings, one can at least determine the highest synergistic combinations for further in vivo studies.

The therapeutic potential of the combination of these three drugs in glioblastoma is clear, which is of clear benefit, as current treatments against glioblastoma remain unsatisfactory. However, the clinical impact of these compounds should be evaluated with further experiments, including in vivo testing, cytotoxicity studies and more molecular studies into the expression of different prognostic markers.

\section{Acknowledgements}

Not applicable.

\section{Funding}

Financial support for this work was provided by a grant from the Fundación Universidad de Navarra (Pamplona, Spain), and predoctoral fellowships from the Asociación de Amigos de la Universidad de Navarra (Pamplona, Spain).

\section{Availability of data and materials}

All data generated or analyzed during this study are included in this published article.

\section{Authors' contributions}

JdlR, AU, BM, JAR, MAI and JSC conceived and designed the experiments. JdlR and AU performed the experiments. IZ and MVZ contributed to the acquisition of clinical data. JdlR, AU and JSC analyzed the data and drafted the manuscript. All authors contributed to revising the final version of the manuscript to be published.

\section{Ethics approval and consent to participate}

The study was approved by the Ethics Committee of the University of Navarra (ref. no. CEI0502012). All samples were fully anonymized prior to accessing.

\section{Patient consent for publication}

Not applicable.

\section{Competing interests}

The authors declare that they have no competing interests.

\section{References}

1. Veliz I, Loo Y, Castillo O, Karachaliou N, Nigro O and Rosell R: Advances and challenges in the molecular biology and treatment of glioblastoma-is there any hope for the future? Ann Transl Med 3: 7, 2015.

2. Verhaak RG, Hoadley KA, Purdom E, Wang V, Qi Y, Wilkerson MD, Miller CR, Ding L, Golub T, Mesirov JP, et al; Cancer Genome Atlas Research Network: Integrated genomic analysis identifies clinically relevant subtypes of glioblastoma characterized by abnormalities in PDGFRA, IDH1, EGFR, and NF1. Cancer Cell 17: 98-110, 2010.

3. Fan TY, Wang H, Xiang P, Liu YW, Li HZ, Lei BX, Yu M and Qi ST: Inhibition of EZH2 reverses chemotherapeutic drug TMZ chemosensitivity in glioblastoma. Int J Clin Exp Pathol 7: 6662-6670, 2014.

4. Network CGAR; Cancer Genome Atlas Research Network: Comprehensive genomic characterization defines human glioblastoma genes and core pathways. Nature 455: 1061-1068, 2008.

5. Lo HW: EGFR-targeted therapy in malignant glioma: Novel aspects and mechanisms of drug resistance. Curr Mol Pharmacol 3: 37-52, 2010.

6. Quick A, Patel D, Hadziahmetovic M, Chakravarti A and Mehta M: Current therapeutic paradigms in glioblastoma. Rev Recent Clin Trials 5: 14-27, 2010.

7. Eyüpoglu IY and Savaskan NE: Epigenetics in Brain Tumors: HDACs Take Center Stage. Curr Neuropharmacol 14: 48-54, 2016.

8. Ferreira WA,PinheiroDR,Costa JuniorCA,Rodrigues-Antunes S, Araújo MD, Leão Barros MB, Teixeira AC, Faro TA, Burbano RR, Oliveira $\mathrm{EH}$, et al: An update on the epigenetics of glioblastomas. Epigenomics 8: 1289-1305, 2016.

9. Gusyatiner O and Hegi ME: Glioma epigenetics: From subclassification to novel treatment options. Semin Cancer Biol 51: 50-58, 2018.

10. Kreth S, Thon N and Kreth FW: Epigenetics in human gliomas. Cancer Lett 342: 185-192, 2014.

11. Yong RL and Tsankova NM: Emerging interplay of genetics and epigenetics in gliomas: A new hope for targeted therapy. Semin Pediatr Neurol 22: 14-22, 2015. 
12. Chen J, Zhang M, Zhang X, Fan L, Liu P, Yu L, Cao X, Qiu S and $\mathrm{Xu}$ Y: EZH2 inhibitor DZNep modulates microglial activation and protects against ischaemic brain injury after experimental stroke. Eur J Pharmacol 857: 172452, 2019.

13. Atadja P: Development of the pan-DAC inhibitor panobinostat (LBH589): Successes and challenges. Cancer Lett 280: 233-241, 2009.

14. Gall Trošelj K, Novak Kujundzic R and Ugarkovic D: Polycomb repressive complex's evolutionary conserved function: The role of EZH2 status and cellular background. Clin Epigenetics 8: 55, 2016.

15. Rao ZY, Cai MY, Yang GF, He LR, Mai SJ, Hua WF, Liao YJ, Deng HX, Chen YC, Guan XY, et al: EZH2 supports ovarian carcinoma cell invasion and/or metastasis via regulation of TGF-beta1 and is a predictor of outcome in ovarian carcinoma patients. Carcinogenesis 31: 1576-1583, 2010.

16. Li K, Liu C, Zhou B, Bi L, Huang H, Lin T and Xu K: Role of $\mathrm{EZH} 2$ in the growth of prostate cancer stem cells isolated from LNCaP cells. Int J Mol Sci 14: 11981-11993, 2013.

17. Zhang Y, Yu X, Chen L, Zhang Z and Feng S: EZH2 overexpression is associated with poor prognosis in patients with glioma. Oncotarget 8: 565-573, 2017.

18. Crea F, Fornaro L, Bocci G, Sun L, Farrar WL, Falcone A and Danesi R: EZH2 inhibition: Targeting the crossroad of tumor invasion and angiogenesis. Cancer Metastasis Rev 31: 753-761, 2012.

19. Hayden A, Johnson PW, Packham G and Crabb SJ: S-adenosylhomocysteine hydrolase inhibition by 3-deazaneplanocin A analogues induces anti-cancer effects in breast cancer cell lines and synergy with both histone deacetylase and HER2 inhibition. Breast Cancer Res Treat 127: 109-119, 2011.

20. Kemp CD, Rao M, Xi S, Inchauste S, Mani H, Fetsch P, Filie A, Zhang M, Hong JA, Walker RL, et al: Polycomb repressor complex-2 is a novel target for mesothelioma therapy. Clin Cancer Res 18: 77-90, 2012.

21. Suvà ML, Riggi $N$, Janiszewska $M$, Radovanovic I, Provero $P$, Stehle JC, Baumer K, Le Bitoux MA, Marino D, Cironi L, et al: $\mathrm{EZH} 2$ is essential for glioblastoma cancer stem cell maintenance. Cancer Res 69: 9211-9218, 2009.

22. Crea F, Hurt EM, Mathews LA, Cabarcas SM, Sun L, Marquez VE, Danesi R and Farrar WL: Pharmacologic disruption of Polycomb Repressive Complex 2 inhibits tumorigenicity and tumor progression in prostate cancer. Mol Cancer 10: 40, 2011

23. Chiba T, Suzuki E, Negishi M, Saraya A, Miyagi S, Konuma T, Tanaka S, Tada M, Kanai F, Imazeki F, et al: 3-Deazaneplanocin $\mathrm{A}$ is a promising therapeutic agent for the eradication of tumor-initiating hepatocellular carcinoma cells. Int J Cancer 130: 2557-2567, 2012.

24. Smits M, Mir SE, Nilsson RJ, van der Stoop PM, Niers JM, Marquez VE, Cloos J, Breakefield XO, Krichevsky AM, Noske DP, et al: Down-regulation of miR-101 in endothelial cells promotes blood vessel formation through reduced repression of EZH2. PLoS One 6: e16282, 2011.

25. Yamagishi $\mathrm{M}$ and Uchimaru K: Targeting EZH2 in cancer therapy. Curr Opin Oncol 29: 375-381, 2017.

26. Yan KS, Lin CY, Liao TW, Peng CM, Lee SC, Liu YJ, Chan WP and Chou RH: EZH2 in Cancer Progression and Potential Application in Cancer Therapy: A Friend or Foe? Int J Mol Sci 18: 18, 2017.

27. Kim KH and Roberts CW: Targeting EZH2 in cancer. Nat Med 22: 128-134, 2016

28. Yu C, Friday BB, Yang L, Atadja P, Wigle D, Sarkaria J and Adjei AA: Mitochondrial Bax translocation partially mediates synergistic cytotoxicity between histone deacetylase inhibitors and proteasome inhibitors in glioma cells. Neuro Oncol 10 309-319, 2008

29. Berghauser Pont LM, Kleijn A, Kloezeman JJ, van den Bossche W, Kaufmann JK, de Vrij J, Leenstra S, Dirven CM and Lamfers ML: The HDAC Inhibitors Scriptaid and LBH589 Combined with the Oncolytic Virus Delta24-RGD Exert Enhanced Anti-Tumor Efficacy in Patient-Derived Glioblastoma Cells. PLoS One 10: e0127058, 2015.

30. Lee EQ, Reardon DA, Schiff D, Drappatz J, Muzikansky A, Grimm SA, Norden AD, Nayak L, Beroukhim R, Rinne ML, et al: Phase II study of panobinostat in combination with bevacizumab for recurrent glioblastoma and anaplastic glioma. Neuro Oncol 17: 862-867, 2015.
31. Pont LM, Naipal K, Kloezeman JJ, Venkatesan S, van den Bent M, van Gent DC, Dirven CM, Kanaar R, Lamfers ML and Leenstra S: DNA damage response and anti-apoptotic proteins predict radiosensitization efficacy of HDAC inhibitors SAHA and LBH589 in patient-derived glioblastoma cells. Cancer Lett 356 (2 Pt B): 525-535, 2015.

32. Singleton WG, Collins AM, Bienemann AS, Killick-Cole CL, Haynes HR, Asby DJ, Butts CP, Wyatt MJ, Barua NU and Gill SS: Convection enhanced delivery of panobinostat (LBH589)-loaded pluronic nano-micelles prolongs survival in the F98 rat glioma model. Int J Nanomedicine 12: 1385-1399, 2017.

33. Yao ZG, Li WH, Hua F, Cheng HX, Zhao MQ, Sun XC, Qin YJ and Li JM: LBH589 Inhibits Glioblastoma Growth and Angiogenesis Through Suppression of HIF-1 $\alpha$ Expression. J Neuropathol Exp Neurol 76: 1000-1007, 2017.

34. Li Y and Seto E: HDACs and HDAC Inhibitors in Cancer Development and Therapy. Cold Spring Harb Perspect Med 6: 6,2016.

35. De Souza C and Chatterji BP: HDAC Inhibitors as Novel Anti-Cancer Therapeutics. Recent Patents Anticancer Drug Discov 10: 145-162, 2015.

36. Turtoi A, Peixoto $\mathrm{P}$, Castronovo $\mathrm{V}$ and Bellahcène A: Histone deacetylases and cancer-associated angiogenesis: Current understanding of the biology and clinical perspectives. Crit Rev Oncog 20: 119-137, 2015.

37. Aum DJ, Kim DH, Beaumont TL, Leuthardt EC, Dunn GP and Kim AH: Molecular and cellular heterogeneity: The hallmark of glioblastoma. Neurosurg Focus 37: E11, 2014.

38. Friedmann-Morvinski D: Glioblastoma heterogeneity and cancer cell plasticity. Crit Rev Oncog 19: 327-336, 2014.

39. Greco WR, Bravo G and Parsons JC: The search for synergy: A critical review from a response surface perspective. Pharmacol Rev 47: 331-385, 1995.

40. Goldin A and Mantel N: The employment of combinations of drugs in the chemotherapy of neoplasia: A review. Cancer Res 17: 635-654, 1957.

41. Chou TC and Talalay P: Quantitative analysis of dose-effect relationships: The combined effects of multiple drugs or enzyme inhibitors. Adv Enzyme Regul 22: 27-55, 1984.

42. Berenbaum MC: Synergy, additivism and antagonism in immunosuppression. A critical review. Clin Exp Immunol 28: 1-18, 1977.

43. Loewe S: Marginal notes on the quantitative pharmacology of combined drugs. Arzneimittelforschung 9: 449-456, 1959 (In German)

44. Chou TC: Theoretical basis, experimental design, and computerized simulation of synergism and antagonism in drug combination studies. Pharmacol Rev 58: 621-681, 2006.

45. Foucquier $\mathbf{J}$ and Guedj M: Analysis of drug combinations: Current methodological landscape. Pharmacol Res Perspect 3: e00149, 2015.

46. Chou TC: Drug combination studies and their synergy quantification using the Chou-Talalay method. Cancer Res 70: 440-446, 2010.

47. Chou $\mathrm{T}$ and Martin N: CompuSyn Software for Drug Combinations and for General Dose Effect Analysis. ComboSyn, Inc., Paramus, NJ, 2007.

48. Johannessen TC, Hasan-Olive MM,Zhu H, Denisova O, Grudic A, Latif MA, Saed H, Varughese JK, Røsland GV, Yang N, et al: Thioridazine inhibits autophagy and sensitizes glioblastoma cells to temozolomide. Int J Cancer 144: 1735-1745, 2019.

49. Smits M, Nilsson J, Mir SE, van der Stoop PM, Hulleman E, Niers JM, de Witt Hamer PC, Marquez VE, Cloos J, Krichevsky AM, et al: miR-101 is down-regulated in glioblastoma resulting in EZH2-induced proliferation, migration, and angiogenesis. Oncotarget 1: 710-720, 2010.

50. Livak KJ and Schmittgen TD: Analysis of relative gene expression data using real-time quantitative PCR and the 2(-Delta Delta C(T)) Method. Methods 25: 402-408, 2001.

51. Lee SY: Temozolomide resistance in glioblastoma multiforme. Genes Dis 3: 198-210, 2016.

52. Fiskus W, Rao R, Balusu R, Ganguly S, Tao J, Sotomayor E, Mudunuru U, Smith JE, Hembruff SL, Atadja P, et al: Superior efficacy of a combined epigenetic therapy against human mantle cell lymphoma cells. Clin Cancer Res 18: 6227-6238, 2012.

53. Fiskus W, Wang Y, Sreekumar A, Buckley KM, Shi H, Jillella A, Ustun C, Rao R, Fernandez P, Chen J, et al: Combined epigenetic therapy with the histone methyltransferase EZH2 inhibitor 3-deazaneplanocin A and the histone deacetylase inhibitor panobinostat against human AML cells. Blood 114: 2733-2743, 2009. 
54. Takashina T, Kinoshita I, Kikuchi J, Shimizu Y, Sakakibara-Konishi J, Oizumi S, Nishimura $M$ and Dosaka-Akita H: Combined inhibition of EZH2 and histone deacetylases as a potential epigenetics therapy for non-small-cell lung cancer cells. Cancer Sci 107: 955-962, 2016.

55. Ding L, Chen S, Liu P, Pan Y, Zhong J, Regan KM, Wang L, Yu C, Rizzardi A, Cheng L, et al: CBP loss cooperates with PTEN haploinsufficiency to drive prostate cancer: Implications for epigenetic therapy. Cancer Res 74: 2050-2061, 2014.

56. Çitışlı V, Dodurga Y, Eroğlu C, Seçme M, Avcı CB and Şatıroğlu-Tufan NL: Temozolomide may induce cell cycle arrest by interacting with URG4/URGCP in SH-SY5Y neuroblastoma cells. Tumour Biol 36: 6765-6772, 2015.

57. Pawlowska E, Szczepanska J, Szatkowska M and Blasiak J: An Interplay between Senescence, Apoptosis and Autophagy in Glioblastoma Multiforme-Role in Pathogenesis and Therapeutic Perspective. Int J Mol Sci 19: 3, 2018.

58. Perazzoli G, Prados J, Ortiz R, Caba O, Cabeza L, Berdasco M, Gónzalez B and Melguizo C: Temozolomide Resistance in Glioblastoma Cell Lines: Implication of MGMT, MMR, P-Glycoprotein and CD133 Expression. PLoS One 10: e0140131, 2015.

59. Dong J, Meng X, Li S, Chen Q, Shi L, Jiang C and Cai J: Risk of adverse vascular events in patients with malignant glioma treated with bevacizumab plus irinotecan: A systematic review and meta-analysis. World Neurosurg 130: e236-e243, 2019.

60. Zhang R, Banik NL and Ray SK: Differential sensitivity of human glioblastoma LN18 (PTEN-positive) and A172 (PTEN-negative) cells to Taxol for apoptosis. Brain Res 1239: 216-225, 2008.
61. Patyka M, Sharifi Z, Petrecca K, Mansure J, Jean-Claude B and Sabri S: Sensitivity to PRIMA-1MET is associated with decreased MGMT in human glioblastoma cells and glioblastoma stem cells irrespective of p53 status. Oncotarget 7: 60245-60269, 2016.

62. Koul D, Wang S, Wu S, Saito N, Zheng S, Gao F, Kaul I, Setoguchi M, Nakayama K, Koyama K, et al: Preclinical therapeutic efficacy of a novel blood-brain barrier-penetrant dual $\mathrm{PI} 3 \mathrm{~K} / \mathrm{mTOR}$ inhibitor with preferential response in PI3K/PTEN mutant glioma. Oncotarget 8: 21741-21753, 2017.

63. Hill VK, Kim JS, James CD and Waldman T: Correction of PTEN mutations in glioblastoma cell lines via AAV-mediated gene editing. PLoS One 12: e0176683, 2017.

64. Muñoz J, Inda MM, Lázcoz P, Zazpe I, Fan X, Alfaro J, Tuñón T, Rey JA and Castresana JS: Promoter Methylation of RASSF1A Associates to Adult Secondary Glioblastomas and Pediatric Glioblastomas. ISRN Neurol 2012: 576578, 2012.

65. de la Rosa J, Urdiciain A, Aznar-Morales JJ, Meléndez B, Rey JA, Idoate MA and Castresana JS: Panobinostat and its combination with 3-deazaneplanocin-A induce apoptosis and inhibit In vitro tumorigenesis and metastasis in GOS-3 glioblastoma cell lines. Cancer Transl Med 4: 39-47, 2018.

66. Forget KJ, Tremblay G and Roucou X: p53 Aggregates penetrate cells and induce the co-aggregation of intracellular p53. PLoS One 8: e69242, 2013. 